\title{
Strong Summer Atmospheric Rivers Trigger Greenland Ice Sheet Melt through Spatially Varying Surface Energy Balance and Cloud Regimes ${ }^{\mathscr{D}}$
}

\author{
Kyle S. Mattingly, ${ }^{\mathrm{a}, \mathrm{g}}$ Thomas L. Mote, ${ }^{\mathrm{a}}$ Xavier Fettweis, ${ }^{\mathrm{b}}$ Dirk van As, ${ }^{\mathrm{c}}$ \\ Kristof VAn Tricht, ${ }^{\mathrm{d}}$ Stef Lhermitte, ${ }^{\mathrm{e}}$ Claire PetTersen, ${ }^{\mathrm{f}}$ And Robert S. FAusto ${ }^{\mathrm{c}}$ \\ ${ }^{a}$ Climatology Research Laboratory, Department of Geography, University of Georgia, Athens, Georgia \\ ${ }^{\mathrm{b}}$ Laboratory of Climatology, Department of Geography, University of Liège, Liège, Belgium \\ ${ }^{\mathrm{c}}$ Geological Survey of Denmark and Greenland, Copenhagen, Denmark \\ d VITO Remote Sensing, Mol, Belgium \\ ${ }^{\mathrm{e}}$ Department of Geoscience and Remote Sensing, Delft University of Technology, Delft, Netherlands \\ ${ }^{\mathrm{f}}$ Space Science and Engineering Center, University of Wisconsin-Madison, Madison, Wisconsin
}

(Manuscript received 14 November 2019, in final form 21 April 2020)

\begin{abstract}
Mass loss from the Greenland Ice Sheet (GrIS) has accelerated over the past two decades, coincident with rapid Arctic warming and increasing moisture transport over Greenland by atmospheric rivers (ARs). Summer ARs affecting western Greenland trigger GrIS melt events, but the physical mechanisms through which ARs induce melt are not well understood. This study elucidates the coupled surface-atmosphere processes by which ARs force GrIS melt through analysis of the surface energy balance (SEB), cloud properties, and local- to synoptic-scale atmospheric conditions during strong summer AR events affecting western Greenland. ARs are identified in MERRA-2 reanalysis (1980-2017) and classified by integrated water vapor transport (IVT) intensity. SEB, cloud, and atmospheric data from regional climate model, observational, reanalysis, and satellitebased datasets are used to analyze melt-inducing physical processes during strong, $>90$ th percentile " $\mathrm{AR}_{90+}$ " events. Near AR "landfall," AR ${ }_{90+}$ days feature increased cloud cover that reduces net shortwave radiation and increases net longwave radiation. As these oppositely signed radiative anomalies partly cancel during $\mathrm{AR}_{90+}$ events, increased melt energy in the ablation zone is primarily provided by turbulent heat fluxes, particularly sensible heat flux. These turbulent heat fluxes are driven by enhanced barrier winds generated by a stronger synoptic pressure gradient combined with an enhanced local temperature contrast between cool over-ice air and the anomalously warm surrounding atmosphere. During $\mathrm{AR}_{90+}$ events in northwest Greenland, anomalous melt is forced remotely through a clear-sky foehn regime produced by downslope flow in eastern Greenland.
\end{abstract}

\section{Introduction}

The Greenland Ice Sheet (GrIS) has experienced substantial mass loss during the past two decades, resulting in an increased contribution to global mean sea level rise (Bamber et al. 2018; Mouginot et al. 2019; Hanna et al. 2020; Shepherd et al. 2020). This mass loss exhibits a large

Supplemental information related to this paper is available at the Journals Online website: https://doi.org/10.1175/JCLI-D-190835.s1.

\footnotetext{
${ }^{\mathrm{g}}$ Current affiliation: Institute of Earth, Ocean, and Atmospheric Sciences, Rutgers, The State University of New Jersey, Piscataway, New Jersey.
}

Corresponding author: Kyle S. Mattingly, kyle.mattingly@rutgers.edu degree of interannual variability, especially pronounced during a period of accelerating mass loss over roughly 2000-12 (van den Broeke et al. 2016). The GrIS loses mass through solid ice discharge and through a reduced surface mass balance (SMB), when increases in surface ablation exceed those in snow accumulation and meltwater refreezing. SMB-related losses were responsible for a greater proportion of total mass loss than ice dynamical processes during the recent GrIS mass loss acceleration (van den Broeke et al. 2017; Mouginot et al. 2019), and model projections indicate that SMB will play the dominant role in future GrIS mass losses (Calov et al. 2018; Rückamp et al. 2018).

GrIS surface melt is driven by energy exchanges at the interface between the ice/snow surface and the atmosphere, and is therefore highly sensitive to atmospheric conditions. A number of atmospheric and coupled ocean-atmospheric 
phenomena, operating across a broad spectrum of spatiotemporal scales, have been found to influence GrIS SMB variability. These include slow-moving anticyclones known as "Greenland blocks" (McLeod and Mote 2016; Ahlstrøm et al. 2017; Hanna et al. 2018a) and extratropical cyclones (McLeod and Mote 2015; Berdahl et al. 2018), whose occurrence has been linked to the state of the North Atlantic Oscillation (NAO) (Fettweis et al. 2013; Hanna et al. 2013; Delhasse et al. 2018) and the Atlantic multidecadal oscillation (AMO) (Rajewicz and Marshall 2014; Auger et al. 2017).

Another recurring feature of the synoptic-scale atmospheric circulation that has been shown to influence GrIS SMB variability is the organization of intense water vapor transport into narrow corridors known as atmospheric rivers (ARs). ARs typically form due to moisture convergence along the cold front in warm sectors of extratropical cyclones (Dacre et al. 2015). A particularly intense AR affected western Greenland during the extreme melt event of mid-July 2012, when nearly the entire ice sheet experienced surface melt for the first time in over a century (Nghiem et al. 2012; Neff et al. 2014; Bonne et al. 2015). Mattingly et al. (2018, hereafter M18) analyzed the influence of ARs on GrIS SMB during 1980-2016, finding that strong $\mathrm{AR}$ events produce intense melt in the low-elevation ablation zone during summer and that ARs affecting western Greenland are responsible for the largest Greenland-wide SMB losses. Recent trends in summer ARrelated moisture transport to western Greenland align with GrIS SMB trends, as enhanced AR activity during 200012 has been followed by more moderate moisture transport by ARs to Greenland in subsequent years (Oltmanns et al. 2019; Mattingly et al. 2016; M18). Climate models project increased moisture transport to the high-latitude Northern Hemisphere under future emissions scenarios (Lavers et al. 2015; Singh et al. 2017), underscoring the importance of understanding interactions between ARs and the ice sheet surface.

Although the influence of ARs on warm season GrIS melt events has been established (M18; Ballinger et al. 2019), the physical mechanisms through which ARs and other features of the synoptic-scale atmospheric circulation induce melt are not well understood. On an annual basis, the absorption of solar radiation is the greatest source of melt energy across the ice sheet (Box et al. 2012). Hofer et al. (2017) found evidence for a decreasing trend in summer cloud cover over Greenland from 1995 to 2009 and deduced that this decrease in cloud cover drove the corresponding negative GrIS mass trend through enhanced shortwave radiation absorption, mainly in the low-albedo ablation zone. However, other studies have found that clouds enhance GrIS surface melt and prevent meltwater refreezing in the accumulation zone through enhanced downwelling longwave radiation (Bennartz et al. 2013; Miller et al. 2015; Van Tricht et al. 2016; Solomon et al. 2017; Cullather and Nowicki 2018; Wang et al. 2018), and future GrIS melt projections are highly sensitive to modeled cloud properties (Hofer et al. 2019). Given the large fluxes of water vapor delivered by ARs, it is likely that some parts of the GrIS experience SMB losses under cloudy conditions during AR events. Additionally, studies of intense melt events in the ablation zone of southern and western Greenland have shown that turbulent fluxes of sensible and latent heat-driven by enhanced wind speeds-are a major source of melt energy and exceed the magnitude of radiative fluxes during these anomalous melt episodes (Braithwaite and Olesen 1990; Fausto et al. 2016a,b; Hermann et al. 2018).

In light of this uncertainty over the physical processes contributing to enhanced GrIS summer melt, in this study we examine the local- to synoptic-scale atmospheric mechanisms and surface-atmosphere interactions that drive GrIS melt during AR events. M18 found that the negative GrIS SMB response is greatest during strong summer ARs affecting western Greenland, and therefore we focus on these events. We first explore the response of the radiative (shortwave and longwave radiation) and turbulent (sensible and latent heat flux) terms of the surface energy balance (SEB) to strong AR events, including the spatial variability of these energy balance components across the GrIS (section 3a). We then analyze the atmospheric processes that produce these SEB responses, focusing on the role of clouds in altering radiative fluxes and the local- to synoptic-scale changes in temperature and pressure fields that produce enhanced wind speeds and turbulent fluxes (sections $3 \mathrm{~b}$ and $3 c)$. As exact values of SEB terms and cloud properties are uncertain over Greenland, we employ a number of observational, regional climate model, reanalysis, and satellitederived datasets to represent the spread of plausible results and highlight areas of agreement and disagreement between data sources. We devote particular attention to a distinct contrast in the processes contributing to melt in the western versus eastern Greenland ablation zone during strong $\mathrm{AR}$ events affecting the higher latitudes of northwest Greenland. This contrast is characterized by simultaneous cloudy, moist conditions over western Greenland and clear, dry downsloping conditions in eastern Greenland, with anomalous melt energy present under both these regimes.

\section{Data and methodology}

\section{a. Data sources}

\section{1) The Regional Climate Model MAR}

The primary data source employed to examine SEB components, near-surface wind fields, and cloud properties 
is the Modèle Atmosphérique Régionale (MAR) (Gallée and Schayes 1994), which has been widely used in GrIS studies (Fettweis et al. 2017). MAR is a coupled atmosphereland surface model that includes the 1D Soil Ice Snow Vegetation Atmosphere Transfer (SISVAT) scheme (De Ridder and Gallée 1998) to calculate mass and energy fluxes between the land surface, snow surface, and atmosphere. Daily outputs from MAR version 3.9.6 (Delhasse et al. 2020), forced with ERA-Interim reanalysis and run at $7.5-\mathrm{km}$ spatial resolution over the period 1980-2017, are used in this study. The ERA-40 radiative scheme is used to compute shortwave and longwave radiative fluxes in MAR (Delhasse et al. 2020). MAR uses a "bulk" parameterization dependent on the temperature and humidity difference between the surface and first MAR vertical level $(\sim 2 \mathrm{~m})$, along with the wind speed, to calculate sensible and latent heat fluxes (De Ridder and Schayes 1997).

MAR has been shown through extensive validation efforts to reproduce near-surface temperatures, melt, and SMB values with a high degree of accuracy over the Greenland and Antarctic ice sheets (Rae et al. 2012; Fettweis et al. 2017; Sutterley et al. 2018; Agosta et al. 2019; Fettweis et al. 2020). The success of the model in simulating these fields may result from compensating biases in SEB, as previous MAR versions have been found to significantly overestimate downwelling shortwave radiation and underestimate downwelling longwave radiation over Greenland due to underestimation of cloudiness (Franco et al. 2013; Fettweis et al. 2017; Delhasse et al. 2020). Net shortwave radiation simulated by the model may also be affected by inaccuracies in albedo, particularly in the low-elevation bare ice zone where the lower limit of albedo is fixed to 0.4 in MAR but has been observed to be 0.2 or lower in some areas (van As et al. 2013; Alexander et al. 2014; Tedesco et al. 2016; Fettweis et al. 2017). According to Delhasse et al. (2020), the version of MAR (3.9.6) used here still has biases in the downward energy fluxes but minimal bias in near-surface temperature, suggesting that there are still some error compensations in the modeled SEB.

Turbulent fluxes of sensible and latent heat from MAR have not been examined as thoroughly as radiative SEB components. Validation of turbulent fluxes is difficult because the single-level bulk method used to calculate them from both model output and PROMICE station observations (see below) likely results in underestimation of their magnitude, particularly during intense melt events in the ablation zone (Fausto et al. 2016b; Hermann et al. 2018). Additionally, the roughness length for momentum $z_{0}$ is a major factor in determining turbulent heat flux values but is poorly constrained in models and observations. Field observations across the $\mathrm{K}$-transect in southwest Greenland have found that $z_{0}$ is approximately uniform $(\sim 0.1-0.5 \mathrm{~mm})$ over snowcovered surfaces in this area but shows a large degree of spatial variability after snowmelt onset in the summer, with end-of-summer $z_{0}$ values ranging from $\sim 10-50 \mathrm{~mm}$ in the lower ablation zone to $\sim 0.01 \mathrm{~mm}$ near the equilibrium line (Smeets and van den Broeke 2008). MAR uses a scheme incorporating surface snow/ice density, snow depth, snow erosion, and sastrugi (ridges of snow formed by wind erosion) to determine $z_{0}$ for turbulent flux calculations, but only for snow-covered surfaces (Alexander et al. 2019), and average $z_{0}$ over the ice sheet in MAR ranges from $\sim 3$ to $6 \mathrm{~mm}$. Similarly, turbulent flux calculations from observations typically use simplified $z_{0}$ values for (snow or) ice surfaces (van As et al. 2012; Fausto et al. 2016a).

In our comparisons with ERA5 and MERRA-2 (Table S1 in the online supplemental material), MAR shows the best overall performance in reproducing the observation-based SEB terms from PROMICE (described in the next subsection). For all variables except LHF (see section 3a) the mean differences between AR categories are greater than the mean MAR bias (cf. Tables S1 and S2), and thus MAR is able to simulate the differences in $\mathrm{SW}_{\text {net }}, \mathrm{LW}_{\text {net }}$, and SHF that occur across AR conditions.

\section{2) Programme For Monitoring of THE GREENLAND ICE SHEET OBSERVATIONS AND DERIVED FLUXES}

Daily average values from Programme for Monitoring of the Greenland Ice Sheet (PROMICE) stations (van As et al. 2011) are used to analyze near-surface atmospheric conditions over the GrIS and for comparison with MAR, reanalysis, and satellite data. PROMICE stations measure downwelling and upwelling longwave and shortwave radiation, and PROMICE also provides derived turbulent fluxes calculated from a 1D surface energy balance model. Similar to MAR, turbulent fluxes are calculated using the bulk method and the observed near-surface gradients in temperature, specific humidity, and wind speed (van As 2011). The model assumes $z_{0}=1 \mathrm{~mm}$ and uses the observed surface temperature to calculate near-surface atmospheric gradients in temperature and humidity, rather than the surface temperature for which all SEB components are in balance.

This study focuses on conditions in the western and northeastern sectors of the GrIS during AR events, and thus data from 11 PROMICE stations located in the Nuuk (NUK), Kangerlussuaq (KAN), Upernavik (UPE), Thule (THU), and Kronprins Christian Land (KPC) regions (Fig. 1, Table 1) are utilized. Most stations are located in the lower ablation zone or in the upper ablation zone near the equilibrium line, with elevations ranging from $220 \mathrm{~m}$ (UPE_L) to $1840 \mathrm{~m}$ (KAN_U) above sea 


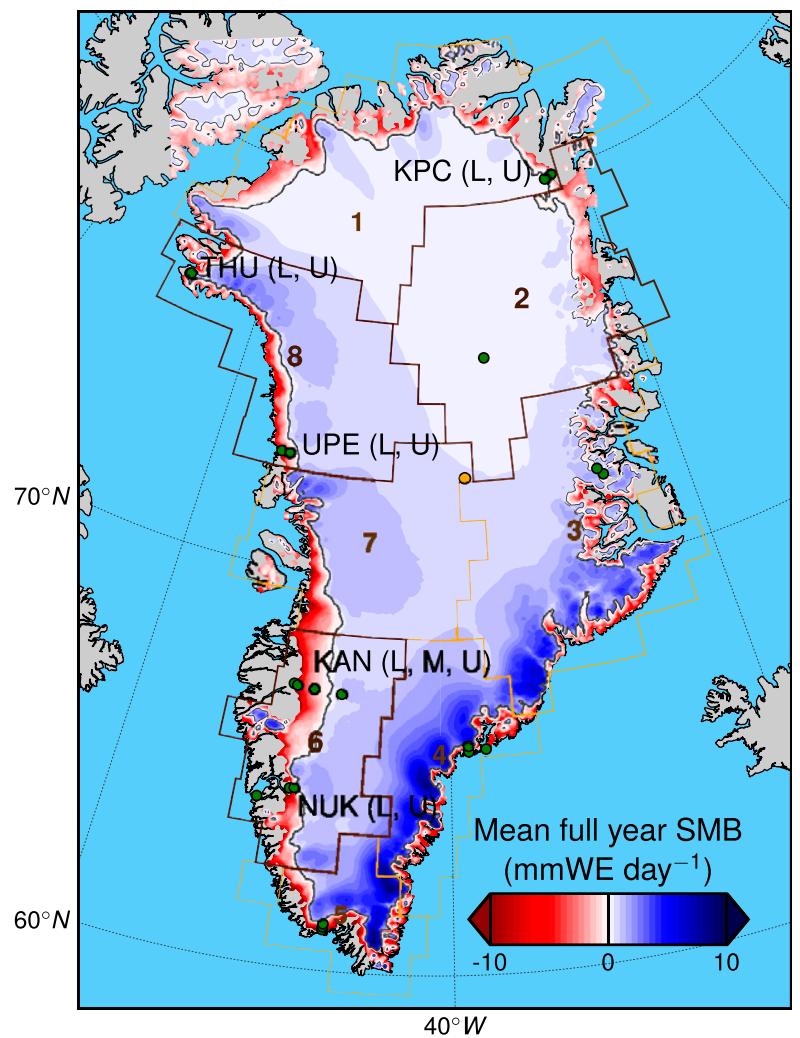

FIG. 1. Annual mean surface mass balance modeled by MAR (19802017), locations of all active PROMICE stations (green dots), and location of Summit Station (orange dot). PROMICE stations utilized in this study are labeled, with stations labeled "L" and "U" the lower and upper station at each site (as well as the middle-elevation station labeled " $\mathrm{M}$ " in the Kangerlussuaq region). Outlines of the eight major GrIS drainage basins are also drawn on the map, with basins 2,6 , and 8 emphasized in this study.

level (Table 1). The chosen stations began recording in years ranging from 2007-10 and observations through summer 2017 are acquired at all stations, resulting in data for 7-10 summers depending on station.

\section{3) MERRA-2 AND ERA5 REANALYSIS DATA}

Modern-Era Retrospective Analysis for Research and Applications, version 2 (MERRA-2) reanalysis data (Gelaro et al. 2017) are used to identify AR events and categorize them based on the intensity of water vapor transport (see section 2b). These MERRA-2 data are interpolated to $0.5^{\circ}$ latitude/longitude resolution, with 6-hourly temporal resolution from 1980-2017. To generate cross section plots of meteorological variables over the GrIS, ERA5 reanalysis data (Copernicus Climate Change Service 2017) on native model vertical levels are used due to their relatively high spatial $\left(0.28125^{\circ}\right)$ and vertical (137 hybrid sigma/pressure levels) resolution (compared with 72 hybrid-eta levels in MERRA-2). ERA5 data for model levels 137-79, extending from the surface up to $\sim 250 \mathrm{hPa}$, are used over the period 2000 17. Additionally, SEB terms and cloud properties from MAR output and PROMICE data are compared with MERRA-2 and ERA5 data.

\section{4) HyBRID RACMO-SATELLITE CLOUd DATA}

To evaluate the accuracy of MAR, ERA5, and MERRA-2 cloud liquid water path (LWP) and ice water path (IWP), a hybrid regional climate model-satellite dataset developed by Van Tricht et al. (2016) is employed. The "hybrid RACMO-satellite" data combine high-accuracy, but temporally limited, active lidar and radar satellite cloud observations - from the Cloud-Aerosol Lidar with Orthogonal Polarization (CALIOP) and Cloud Profiling Radar (CPR) sensors aboard the CALIPSO and CloudSat satellites-with hourly (but less accurate) LWP and IWP output from version 2.3 of the RACMO regional climate model (Noël et al. 2015). The spatiotemporal dynamics of clouds in this dataset are driven by RACMO2.3, and biases in cloud properties are subsequently reduced (but not eliminated) by rescaling the model output to more

TABLE 1. Start date of observations, elevation (m ASL), and percentage of valid observations (from start date through 2019) at each of the 11 PROMICE stations utilized in this study for meteorological variables: air pressure, air temperature, relative humidity (RH), wind speed, incoming shortwave radiation ( $\mathrm{SW}$ in), outgoing shortwave radiation (SW out), incoming longwave radiation (LW in), and outgoing longwave radiation (LW out).

\begin{tabular}{|c|c|c|c|c|c|c|c|c|c|c|}
\hline Station & Start date & Elevation & Air pressure & Air temperature & RH & Wind speed & SW in & SW out & $\mathrm{LW}$ in & LW out \\
\hline KPC_L & $17 \mathrm{Jul} 2008$ & 370 & $63.2 \%$ & $75.5 \%$ & $75.5 \%$ & $75.7 \%$ & $75.5 \%$ & $75.5 \%$ & $75.2 \%$ & $75.5 \%$ \\
\hline KPC_U & 17 Jul 2008 & 870 & $99.3 \%$ & $99.3 \%$ & $99.3 \%$ & $99.3 \%$ & $99.3 \%$ & $99.3 \%$ & $98.3 \%$ & $98.8 \%$ \\
\hline NUK_L & 20 Aug 2007 & 530 & $97.4 \%$ & $97.4 \%$ & $97.4 \%$ & $97.3 \%$ & $93.0 \%$ & $92.9 \%$ & $76.1 \%$ & $90.7 \%$ \\
\hline NUK_U & 20 Aug 2007 & 1120 & $76.7 \%$ & $76.7 \%$ & $76.7 \%$ & $76.7 \%$ & $76.7 \%$ & $76.7 \%$ & $91.3 \%$ & $75.4 \%$ \\
\hline KAN_L & 1 Sep 2008 & 670 & $99.9 \%$ & $99.9 \%$ & $99.9 \%$ & $99.9 \%$ & $99.9 \%$ & $99.9 \%$ & $99.7 \%$ & $99.4 \%$ \\
\hline KAN_M & 2 Sep 2008 & 1270 & $93.7 \%$ & $93.8 \%$ & $93.6 \%$ & $93.8 \%$ & $93.7 \%$ & $93.7 \%$ & $93.5 \%$ & $93.7 \%$ \\
\hline KAN_U & 4 Apr 2009 & 1840 & $95.8 \%$ & $95.8 \%$ & $95.8 \%$ & $95.8 \%$ & $95.8 \%$ & $95.8 \%$ & $95.6 \%$ & $95.6 \%$ \\
\hline UPE_L & 17 Aug 2009 & 220 & $99.1 \%$ & $99.2 \%$ & $99.1 \%$ & $99.2 \%$ & $99.1 \%$ & $99.1 \%$ & $98.9 \%$ & $97.9 \%$ \\
\hline UPE_U & 17 Aug 2009 & 940 & $99.7 \%$ & $99.7 \%$ & $99.7 \%$ & $99.7 \%$ & $99.7 \%$ & $99.7 \%$ & $99.7 \%$ & $98.9 \%$ \\
\hline THU_L & 9 Aug 2010 & 570 & $72.2 \%$ & $88.3 \%$ & $72.1 \%$ & $88.3 \%$ & $72.2 \%$ & $72.2 \%$ & $72.0 \%$ & $71.7 \%$ \\
\hline THU_U & 9 Aug 2010 & 760 & $93.9 \%$ & $90.6 \%$ & $90.4 \%$ & $94.3 \%$ & $90.4 \%$ & $90.4 \%$ & $89.3 \%$ & $89.7 \%$ \\
\hline
\end{tabular}




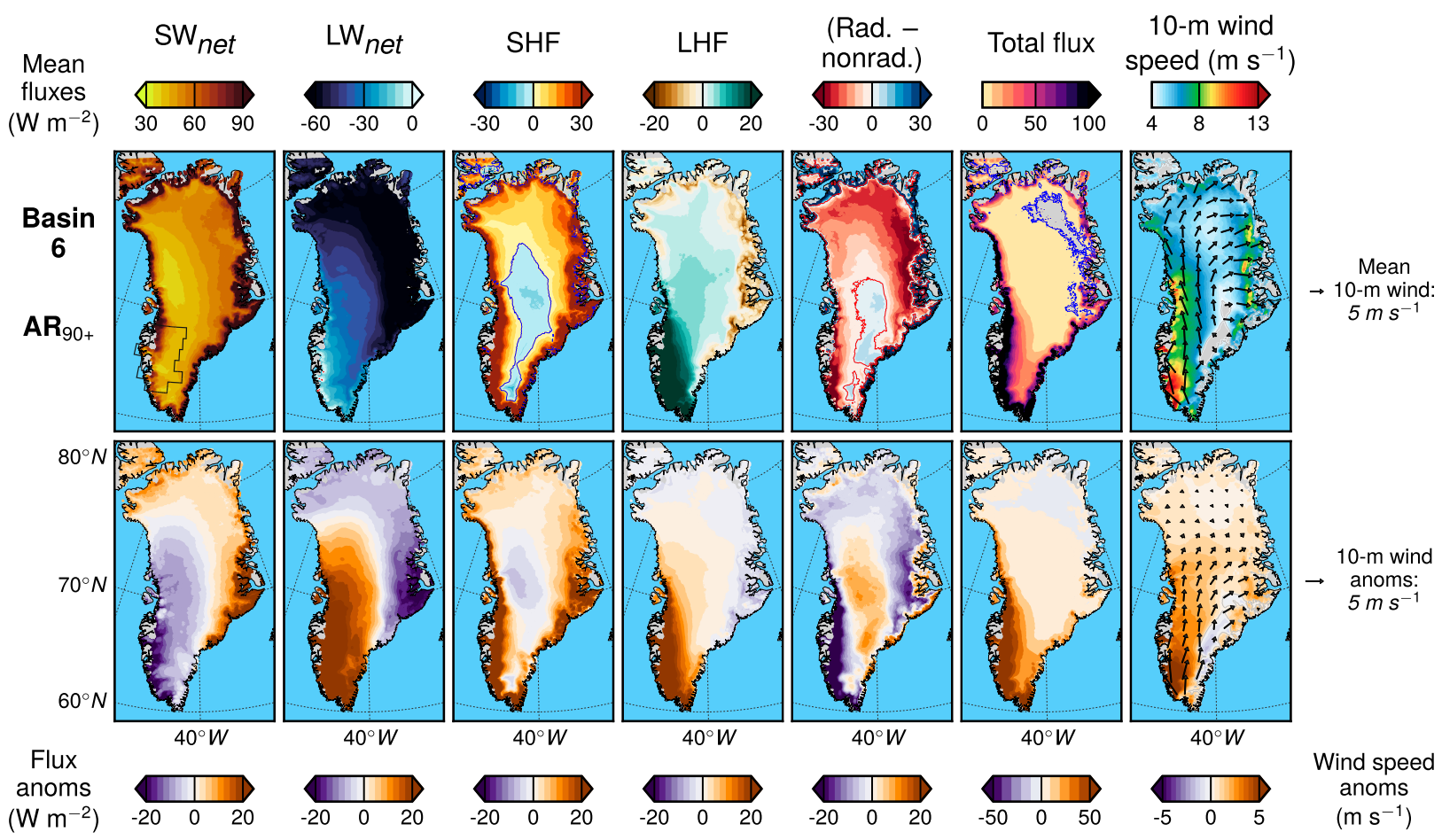

FIG. 2. Surface energy balance terms from MAR: (top) composite means and (bottom) anomalies on AR $90+$ days in basin 6 . Also included are composite mean and anomalies of the difference between summed radiative and nonradiative flux terms (rad. - nonrad.), the sum of all terms (total flux), and maps of $10-\mathrm{m}$ wind speed and direction.

closely match available satellite observations. These data are aggregated onto a $2^{\circ} \times 2^{\circ}$ grid during $2007-10$, with 3-hourly temporal resolution that is resampled to daily means in the present study. Further details are provided by Van Tricht et al. (2016), who find that the hybrid RACMO-satellite dataset slightly underestimates LWP but agrees significantly better with groundbased LWP retrievals from Summit Station than raw RACMO2.3 output.

\section{5) Summit Station ClOUd LiQuid WATER PATH RETRIEVALS}

To provide an additional check on the model and reanalysis cloud data, LWP retrievals from Summit Station, located in the high-elevation dry snow zone of the central GrIS (Shupe et al. 2013; see Fig. 1), are utilized. LWP values are estimated by applying a physical retrieval algorithm to radiances measured by a pair of microwave radiometers at two low-frequency channels (23.84 and $31.40 \mathrm{GHz})$ and one high-frequency channel $(90.0 \mathrm{GHz})$ (Turner et al. 2007; Pettersen et al. 2016; Miller et al. 2017). The addition of the high-frequency channel helps constrain LWP when little cloud liquid is present, reducing mean LWP uncertainty to $\sim 5 \mathrm{~g} \mathrm{~m}^{-2}$ (Pettersen et al. 2018). LWP retrievals from July 2010 through August 2017 are resampled to daily mean temporal resolution in this study.

\section{b. Methods}

\section{1) ATMOSPHERIC RIVER IDENTIFICATION AND INTENSITY CLASSIFICATION}

Following M18, outlines of AR features over the Northern Hemisphere are identified at 6-hourly time steps using integrated water vapor transport (IVT) calculated from MERRA-2 and interpolated to $0.5^{\circ}$ latitude/ longitude resolution. See M18, Table S3, and Fig. S1 for additional details and examples of the AR identification criteria, which are similar to those of Guan and Waliser (2015) and Mundhenk et al. (2016a), with the notable exceptions of a lesser minimum IVT threshold $\left(150 \mathrm{~kg} \mathrm{~m}^{-1} \mathrm{~s}^{-1}\right)$ and allowance for northerly moisture transport from the Arctic. Both of these unique criteria are designed to capture the specific characteristics of ARs impacting Greenland.

To compare atmospheric processes during intense AR events to periods with ARs of lesser intensity or no AR present, outlines of the eight major GrIS drainage basins from Luthcke et al. (2013) are delineated (Fig. 1), and each day is classified into one of three categories (no $\mathrm{AR}, \mathrm{AR}_{<90}, \mathrm{AR}_{90+}$ ) based on basin-scale $\mathrm{AR}$ intensity. If an AR outline overlaps with a given basin outline on a given day, that basin is classed as experiencing an AR "landfall," while no AR days have no AR present. 


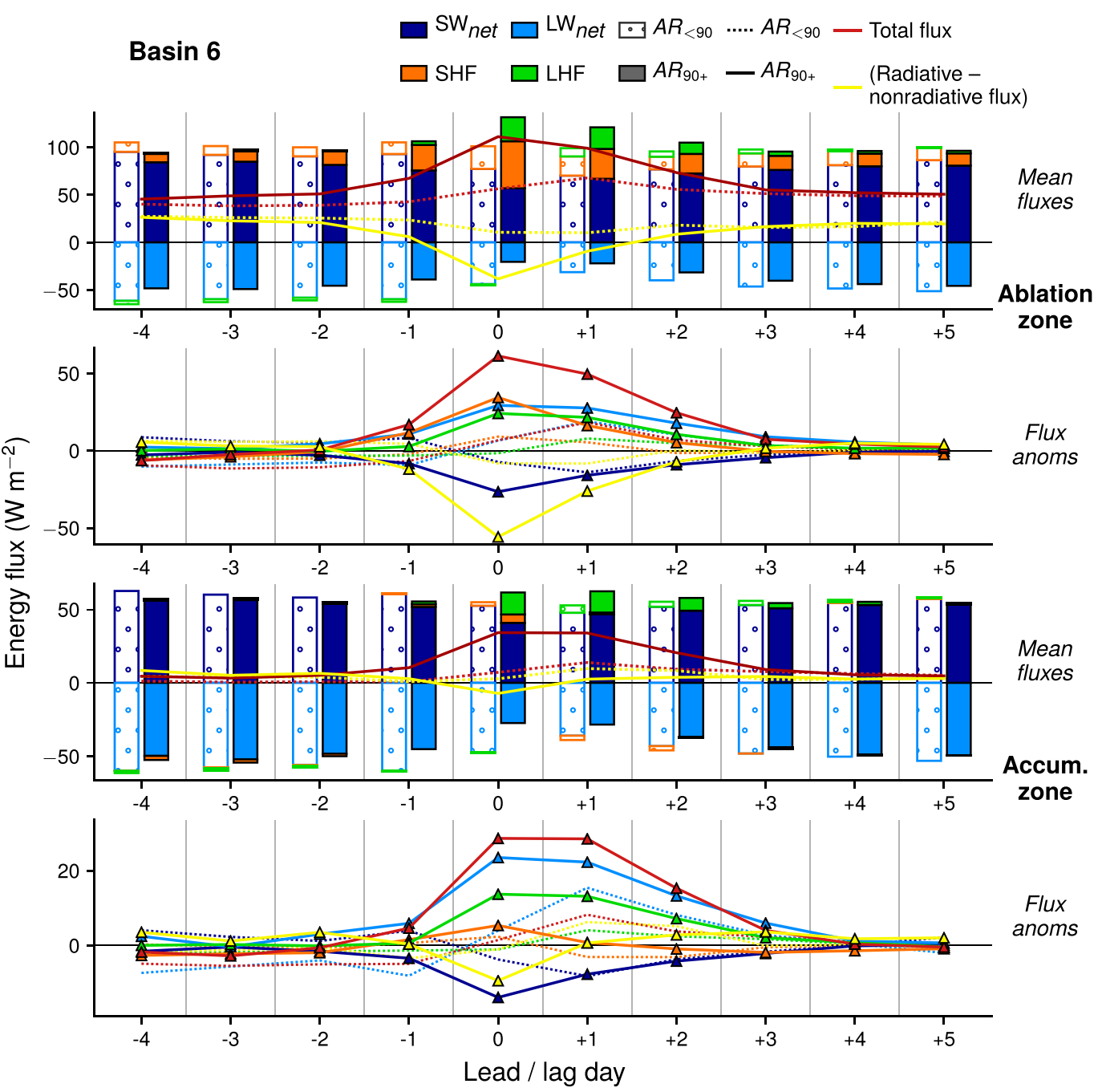

FIG. 3. Composite mean and anomalies of MAR surface energy balance terms averaged over the ablation zone and accumulation zone of basin 6 for the days surrounding $\mathrm{AR}_{<90}$ and $\mathrm{AR}_{90+}$ events. Also plotted is the difference between summed radiative and nonradiative flux terms (yellow lines) and the sum of all terms (red lines).

To categorize $\mathrm{AR}_{<90}$ and $\mathrm{AR}_{90+}$ days, the distribution of maximum IVT values within the area of overlap between the AR and basin outline on days an AR is present is compiled for each season. $\mathrm{AR}_{<90}\left(\mathrm{AR}_{90+}\right)$ days are those with an AR whose maximum IVT is less (greater) than the 90th percentile of this basin- and season-specific distribution. The 90th percentile IVT threshold was chosen because warm, moist, windy conditions at low-elevation PROMICE stations are much more frequent during $\mathrm{AR}_{90+}$ events (see appendix).

\section{2) AtMospheric COMPOSITE ANALYSES}

Mean SEB terms on no $\mathrm{AR}, \mathrm{AR}_{<90}$, and $\mathrm{AR}_{90+}$ days in basins 6 and 8 are calculated from MAR daily output during the summer months (JJA) of 1980-2017. Differences between summed radiative ( $\mathrm{SW}_{\text {net }}$ and $\left.\mathrm{LW}_{\text {net }}\right)$ versus turbulent heat (SHF and LHF) fluxes, as well as total melt energy $\left(\mathrm{SW}_{\text {net }}+\mathrm{LW}_{\text {net }}+\mathrm{SHF}+\mathrm{LHF}\right)$, are also compiled. Rain energy flux and conductive ground heat flux are not examined due to lack of available data on these SEB terms from MAR and PROMICE. These energy sources are generally negligible on seasonal time scales in comparison to radiative and turbulent fluxes (Charalampidis et al. 2015), although rain heat flux may be an important factor contributing to melt in some cases. Doyle et al. (2015) calculated that raininduced ice melt generated $\sim 0.5 \%$ of the runoff at a lower ablation zone site near Kangerlussuaq during an August 2011 rainfall event, while Fausto et al. (2016a) found that the rain heat flux contributed an average of 


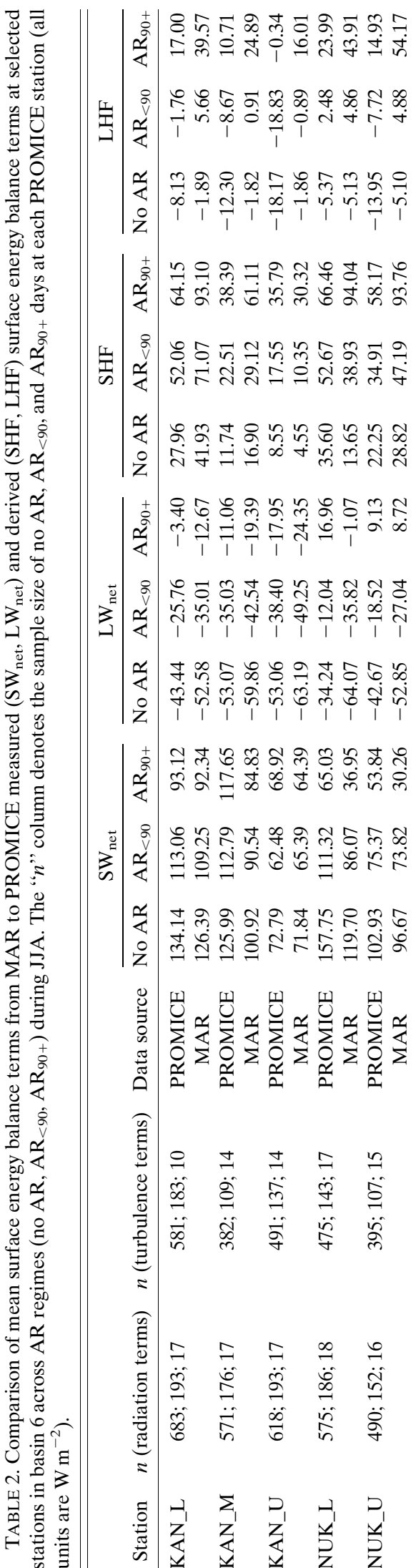

$7 \%$ of melt energy during two major melt events in summer 2012 at the QAS_L PROMICE station in South Greenland (compared to an average JJA contribution of 1\%). However, Doyle et al. (2015) calculated that warm rainfall can efficiently heat the colder snowpack found at higher ice sheet elevations to the freezing point, and Fausto et al. (2016b) noted that models may underestimate rain heat flux by assuming rain temperature is the same as surface temperature despite the presence of temperature inversions. Therefore it is possible that rain energy flux contributes substantially to melt during AR events, particularly in higher elevations with a cold pre-existing snowpack.

To examine SEB evolution throughout AR events, spatially averaged means and anomalies of SEB components are compiled over the ablation and accumulation zones for \pm 5 days surrounding $\mathrm{AR}_{<90}$ and $\mathrm{AR}_{90+}$ events. In these composites, the window is "broken" when another AR of equal or greater intensity occurs. For example, if day 0 is an $\mathrm{AR}_{90+}$ day and $\mathrm{AR}_{90+}$ events also occur on day -5 , day -3 , and day +3 , only days from -2 through +2 are included. The ablation and accumulation zones are areas where MAR annual mean SMB (1980-2017) is less than or greater than $0 \mathrm{mmWE}$, respectively (Fig. 1). Composites are also produced for basin 2 during basin $8 \mathrm{AR}$ events to examine northeast Greenland melt forced by downsloping airflow during northwest Greenland AR events.

Comparisons between PROMICE, MAR, ERA5, and MERRA-2 radiative and turbulent fluxes are performed for PROMICE stations in basin 6 (KAN_L, KAN_M, KAN_U, NUK_L, NUK_U) and basin 8 (THU_L, THU_U, UPE_L, UPE_U), as well as two basin 1 stations (KPC_L, KPC_U). Because KPC_L and $\mathrm{KPC}_{-} \mathrm{U}$ are near the boundary between basin 1 and basin 2, and conditions at these stations are likely similar to those in the basin 2 ablation zone, the SEB at these stations is analyzed in relation to AR activity in basin 8 .

Composite mean and anomaly maps of cloud properties (cloud cover, liquid water path, and ice water path) from MAR are produced in the same manner as the SEB analysis described above. These cloud properties are compared to ERA5 and MERRA-2 during 2000-17, to the hybrid RACMO-satellite LWP and IWP data during 2007-10, and to groundbased retrievals from Summit Station during 2010-17.

Vertical cross sections of atmospheric variables relevant to cloud formation, the atmospheric thermal state, and wind fields are compiled across AR 

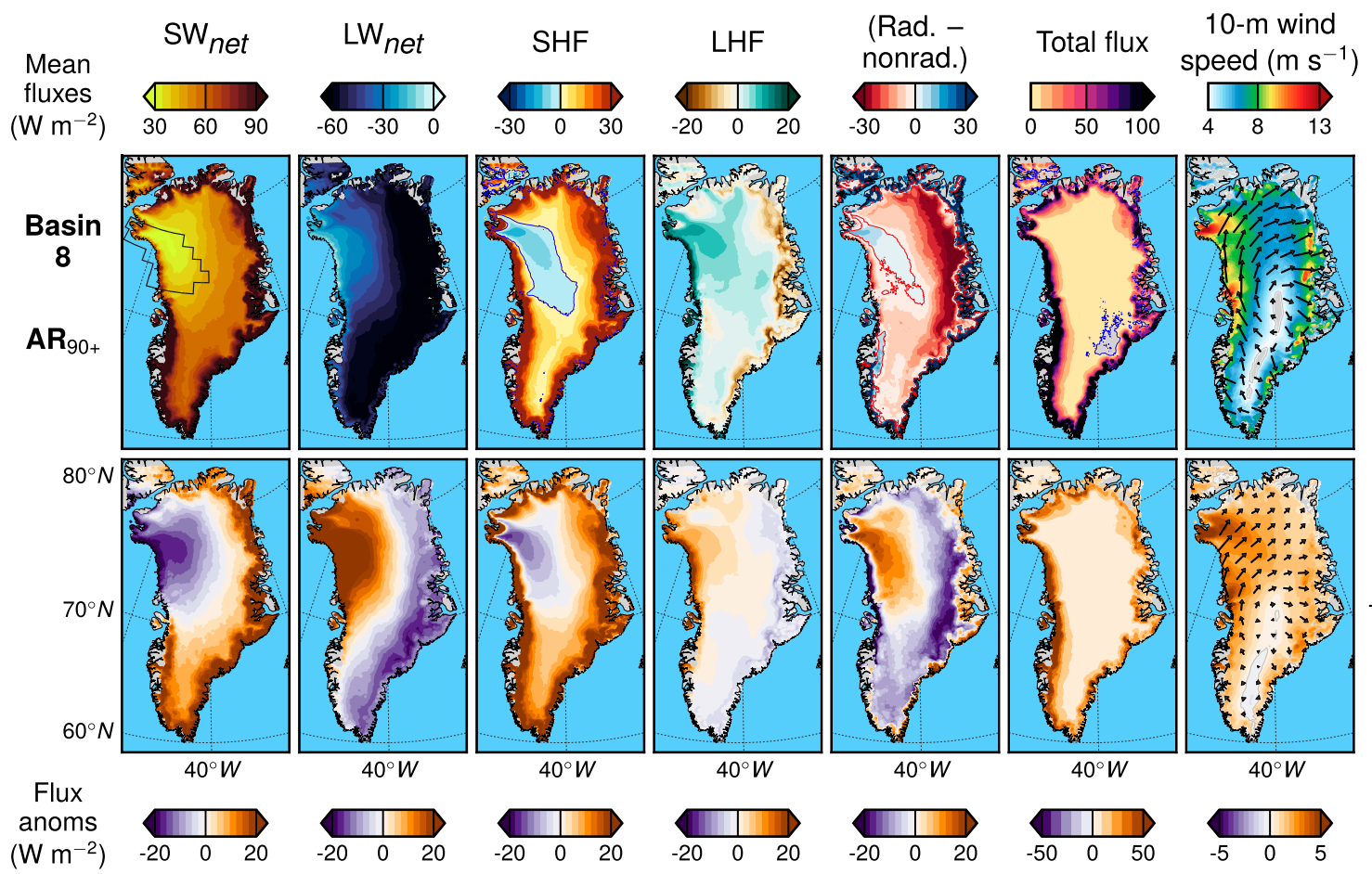

FIG. 4. As in Fig. 2, but for basin $8 \mathrm{AR}_{90+}$ days.

categories from ERA5 data during 2000-17 (section 3c). Synoptic-scale composites of near-surface and midtropospheric $(500 \mathrm{hPa})$ pressure, wind, temperature, and moisture conditions for distinct AR categories are produced using MERRA-2. For the cloud comparison analyses, cross sections, and synoptic composites, the sample sizes of the no AR and $\mathrm{AR}_{<90}$ categories are reduced to match the number of days in the $\mathrm{AR}_{90+}$ category, using a random number generator to select no AR and $\mathrm{AR}_{<90}$ days to sample for composites.

\section{Results}

\section{a. Surface energy balance during AR events}

During $\mathrm{AR}_{90+}$ events affecting basin 6 (southwest Greenland), negative $\mathrm{SW}_{\text {net }}$ anomalies and positive $\mathrm{LW}_{\text {net }}$ anomalies are modeled by MAR throughout this basin (Fig. 2). Positive energy flux anomalies begin 1 day prior to the date of $\mathrm{AR}_{90+}$ impact (day -1), with anomalies lingering for around 2 additional days (through day +2 ) on average (Fig. 3). MAR shows strong positive sensible heat fluxes (ranging from 60 to $90+\mathrm{W} \mathrm{m}^{-2}$ ) in the ablation zone (Table 2), transitioning to weakly positive or weakly negative SHF in the higher elevations of the accumulation zone. SHF values are greatest in the ablation zone due to the anomalously strong southerly winds at lower elevations (Fig. 2), combined with the enhanced thermal contrast between the ice surface and near-ice atmosphere in the presence of warm air advection (Fig. S2; section 3c) and greater aerodynamic roughness length in snow-free areas (see section 2a).

Substantial LHF (on the order of $25-50+\mathrm{W} \mathrm{m}^{-2}$ ) is also modeled by MAR over the ablation zone and lower accumulation zone of basin 6. However, these LHF values are much higher than those derived from PROMICE observations (which range from $\sim 10$ to $25 \mathrm{~W} \mathrm{~m}^{-2}$ in the ablation zone; see Table 2) and simulated by ERA5 and MERRA-2 (Fig. S4). This suggests that LHF in lower elevations is likely overestimated by MAR, and even in MAR the SHF is 2-3 times larger than LHF in the basin 6 ablation zone. Thus SHF is the dominant source of turbulent energy flux in the basin 6 ablation zone during $\mathrm{AR}_{90+}$ events. It is notable, however, that LHF shifts from a negative (energy lost through evaporation/sublimation) to positive (energy gained from condensation/deposition) regime when comparing no $\mathrm{AR}$ to $\mathrm{AR}_{90+}$ conditions throughout the basin 6 ablation zone (Table 2).

The magnitude of the summed turbulent flux terms exceeds net radiation by up to $30 \mathrm{~W} \mathrm{~m}^{-2}$ in much of the ablation zone on basin $6 \mathrm{AR}_{90+}$ days according to MAR (Figs. 2 and 3), in agreement with prior studies (e.g., Braithwaite and Olesen 1990; Fausto et al. 2016b) finding that the majority of melt energy is contributed by nonradiative fluxes during intense melt events in the 


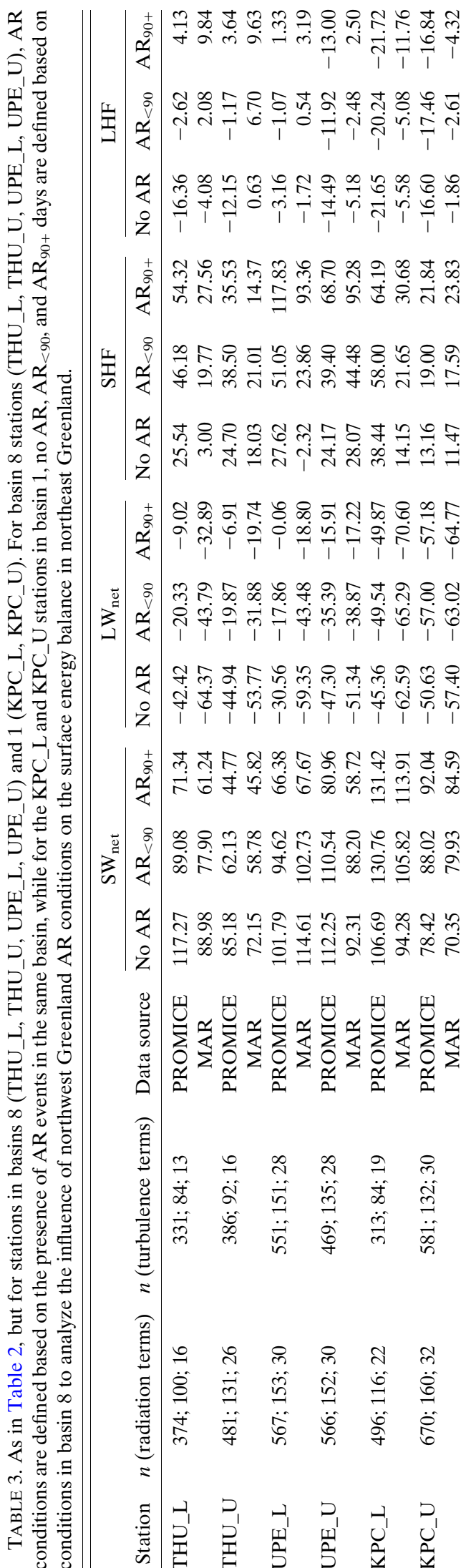

southwest Greenland ablation zone. In interpreting this result, it must be reiterated that both MAR and PROMICE turbulent heat flux values are derived using SEB models with significant uncertainties, particularly relating to aerodynamic roughness length $z_{0}$ values (section 2a). Neither MAR nor PROMICE turbulent fluxes thus represent "true" values, and it is likely that the single-level bulk flux calculation method used in both the PROMICE and MAR turbulent flux derivations underestimates the magnitude of heat transfer to the surface by turbulent fluxes, especially in the lower ablation zone during periods of intense warm air advection and melt (Fausto et al. 2016b; Hermann et al. 2018).

In the accumulation zone, turbulent fluxes of sensible and latent heat are reduced relative to the ablation zone due to lower wind speeds, lesser (or negative) surfaceatmosphere temperature contrast, smaller aerodynamic roughness lengths (Smeets and van den Broeke 2008), and decreased atmospheric water vapor content. The lesser melt energy anomalies (on the order of $10-30 \mathrm{~W} \mathrm{~m}^{-2}$, compared to $50-60 \mathrm{~W} \mathrm{~m}^{-2}$ in the ablation zone) are primarily produced by increased $\mathrm{LW}_{\text {net }}$ that is not compensated by an equivalent decrease in $\mathrm{SW}_{\text {net }}$ (Figs. 2 and 3). MAR also simulates substantial positive melt energy contributions from LHF in the accumulation zone, but KAN_U observationally derived LHF along with ERA5 and MERRA-2 data indicate that LHF values are less negative rather than absolutely positive on $\mathrm{AR}_{90+}$ days.

In northwest Greenland, $\mathrm{AR}_{90+}$ events affecting basin 8 produce qualitatively similar changes to the SEB in the immediate vicinity of AR landfall as the corresponding events in basin 6 (Fig. 4, Fig. S3, Table 3). However, basin $8 \mathrm{AR}_{90+}$ events are also accompanied by positive anomalies in melt energy throughout the northern and northeastern GrIS ablation zone that are not present during basin $6 \mathrm{AR}$ events (Fig. 5). The anomalous energy fluxes in basin 2 are produced by changes in SEB terms that contrast with the AR landfall area in northwest Greenland (basin 8). Positive $\mathrm{SW}_{\text {net }}$ anomalies, negative $\mathrm{LW}_{\text {net }}$ anomalies, strong positive SHF anomalies, and negative LHF anomalies occur along the northeastern and eastern margin of the GrIS. The positive $\mathrm{SW}_{\text {net }}$ anomalies peak on the day of basin $8 \mathrm{AR}_{90+}$ events (day 0 ) and the day after (day +1 ) and SHF peaks on day +1 , resulting in the highest energy flux anomalies on the day after $\mathrm{AR}_{90+}$ events. The day 0 maximum of $\mathrm{SW}_{\text {net }}$ suggests preconditioning of the surface for melt in NE Greenland by clearing and warming conditions prior to the arrival of the highest temperature anomalies associated with the $\mathrm{AR}_{90+}$ from days $+1-3$. Melt energy anomalies last longer than in 


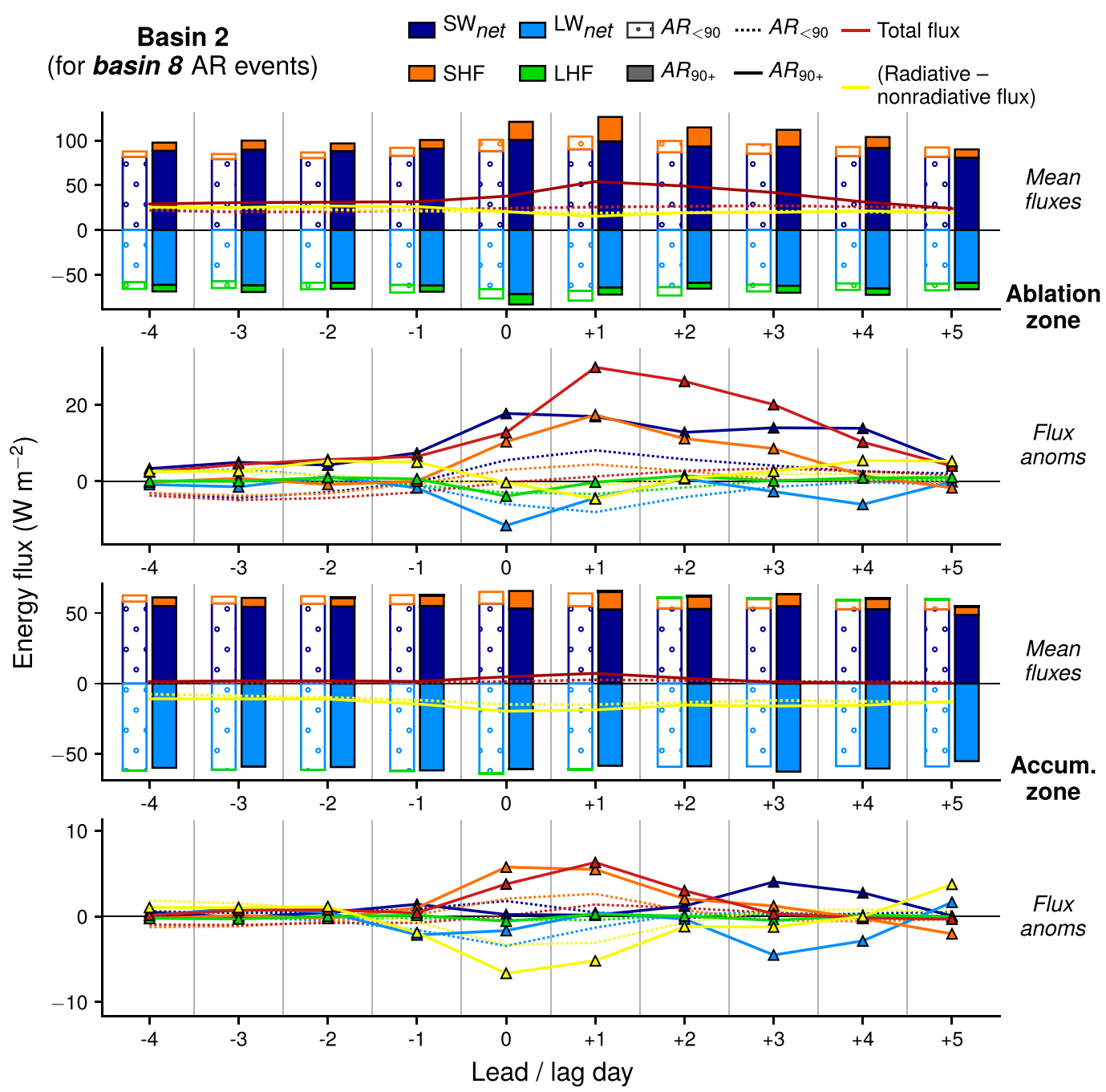

FIG. 5. As in Fig. 3, except that quantities plotted are averaged over the ablation and accumulation zones of basin 2 during AR events over basin 8 .

basin 8 , with energy fluxes slowly returning to preevent values by day +5 (Fig. 5 ).

\section{b. Cloud properties during AR events}

Having described the SEB changes that occur during $\mathrm{AR}_{90+}$ events, we now analyze the atmospheric processes that produce these anomalous energy fluxes. We begin by examining the impact of clouds on radiative fluxes. On $\mathrm{AR}_{90+}$ days in basin 6, MAR simulates extensive cloud cover throughout the basin and surrounding areas, with up to $30 \%-40 \%$ more cloud cover on average compared to no AR days (Fig. 6). The radiative impact of these clouds is likely to be greatest in the accumulation zone where high surface albedo damps the cloud shortwave shading effect (W. Wang et al. 2019), and during nighttime hours when clear-sky shortwave radiation is lowest or zero and clouds inhibit meltwater refreezing and precondition the ice sheet surface for daytime melt (Van Tricht et al. 2016; Solomon et al. 2017). Although we do not analyze the height of cloud bases in this study, these LWP values are likely to be associated with lower altitude and warmer clouds, also contributing to the warming effect. Except over the lower ablation zone, MAR simulates clouds with little liquid water over the GrIS. LWP values in the $10-40 \mathrm{~g} \mathrm{~m}^{-2}$ range have been shown to maximize positive cloud radiative effects by enhancing downward longwave radiation while allowing some shortwave radiation to filter through (Bennartz et al. 2013; Van Tricht et al. 2016; Nicolas et al. 2017). MAR produces these LWP values over only a narrow band of the lower accumulation zone during $\mathrm{AR}_{90+}$ 


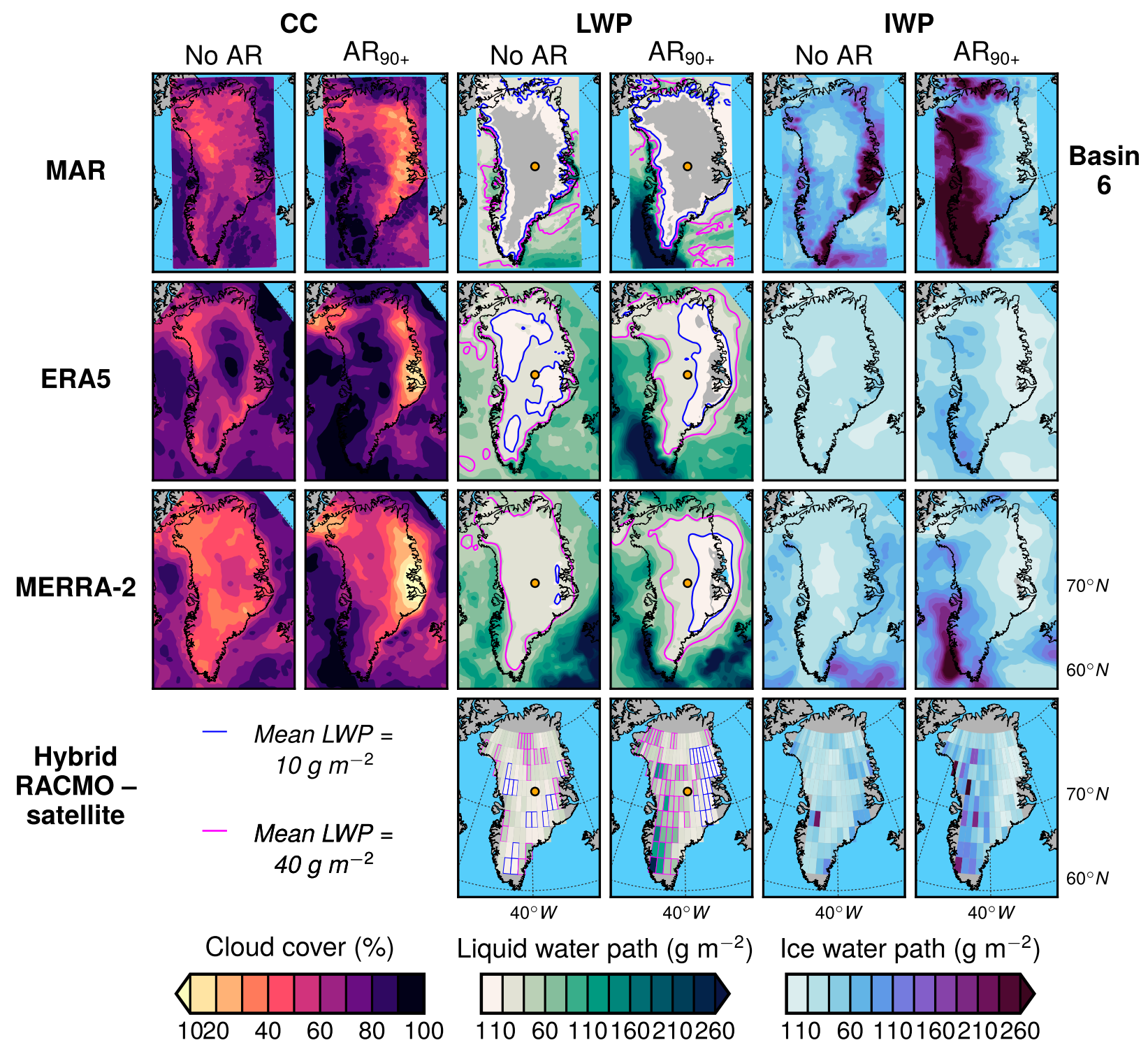

FIG. 6. Comparison of mean cloud cover (CC), cloud liquid water path (LWP), and cloud ice water path (IWP) from MAR, ERA5, MERRA-2, and hybrid RACMO-satellite data on no AR and $\mathrm{AR}_{90+}$ days in basin 6 during 2010-17. Contours of 10 and $_{40} \mathrm{~g} \mathrm{~m}^{-2}$ values $^{-}$ are plotted on the LWP maps in blue and pink, respectively (on hybrid RACMO-satellite maps, grid cells with $<10 \mathrm{~g} \mathrm{~m}^{-2} \mathrm{LWP}_{\text {are }}$ outlined in blue and $>40 \mathrm{~g} \mathrm{~m}^{-2}$ LWP in pink). The location of Summit Station is plotted with an orange dot on LWP maps.

events, instead simulating high IWP values over the western GrIS.

In agreement with MAR, ERA5 and MERRA-2 show large increases in cloud cover over basin 6 on $\mathrm{AR}_{90+}$ days compared to no AR days (Fig. 6). Their depiction of cloud liquid and ice water differs substantially from MAR, however. Both ERA5 and MERRA-2 show LWP $>10 \mathrm{~g} \mathrm{~m}^{-2}$ over all but the eastern interior GrIS on $\mathrm{AR}_{90+}$ days, and LWP $>40 \mathrm{~g} \mathrm{~m}^{-2}$ extending well into the higher elevations of the accumulation zone in basin 6. ERA5 depicts modest IWP values of $30-90 \mathrm{~g} \mathrm{~m}^{-2}$ over most of basin 6, while MERRA-2 depicts higher IWP values $\left(100-200 \mathrm{~g} \mathrm{~m}^{-2}\right)$, which are nevertheless much lower than the $>250 \mathrm{~g} \mathrm{~m}^{-2}$ MAR values. ERA5 cross sections suggest that cloud liquid water tends to concentrate $50-100 \mathrm{hPa}$ above the ice sheet surface on $\mathrm{AR}_{90+}$ days, while ice clouds spread more diffusely throughout the middle and upper troposphere (Figs. S6 and S7).

Comparisons with the hybrid RACMO-satellite data (Fig. 6) and Summit Station LWP retrievals (Table 4) show that the ERA5 and MERRA-2 LWP and IWP values are more realistic than the MAR output. The spatial patterns of LWP and IWP in the hybrid RACMO-satellite data are 
TABLE 4. Comparison of daily mean liquid water path $\left(\mathrm{g} \mathrm{m}^{-2}\right)$ retrievals from Summit Station with MAR, ERA5, and MERRA-2 data across categories of AR activity in basin 6 during JJA. The " $n$ " column denotes the sample size of no AR, AR $<90$, and AR ${ }_{90+}$ days during the 2010-17 period of overlapping data. The mean uncertainty value for each AR category is also included for the Summit LWP data.

\begin{tabular}{lrcccrr}
\hline \hline & $n$ & Summit LWP (mean) & Summit LWP (mean uncertainty) & MAR LWP & ERA5 LWP & MERRA-2 LWP \\
\hline No AR & 383 & 12.85 & 4.50 & 0.23 & 9.26 & 14.66 \\
$\mathrm{AR}_{<90}$ & 127 & 21.23 & 4.51 & 0.20 & 11.50 & 17.84 \\
$\mathrm{AR}_{90+}$ & 16 & 35.66 & 4.53 & 0.55 & 18.99 & 21.85 \\
\hline
\end{tabular}

reproduced well by ERA5 and MERRA-2, with higher amounts of LWP and IWP across the western GrIS during $\mathrm{AR}_{90+}$ events compared to no AR conditions. This westto-east gradient in LWP aligns with other studies showing that snowfall from clouds containing liquid water is more frequent over western than eastern Greenland during summer, and that snow-producing clouds containing liquid water at Summit Station tend to be produced by air masses that first pass over southwest Greenland (Pettersen et al. 2018; McIlhattan et al. 2019). LWP appears to still be underestimated by ERA5 and MERRA-2 on AR $_{90+}$ days, with LWP $>40 \mathrm{~g} \mathrm{~m}^{-2}$ extending to higher elevations of the western GrIS accumulation zone in the hybrid RACMOsatellite product compared with ERA5 and MERRA-2. This is confirmed by Summit Station LWP retrievals, as mean ERA5 and MERRA-2 LWP is within the range of the observational uncertainty on no AR days but $15-20 \mathrm{~g} \mathrm{~m}^{-2}$ lower than the ground-based retrievals on $\mathrm{AR}_{90+}$ days (Table 4). Previous studies (e.g., Forbes and Ahlgrimm 2014; Lenaerts et al. 2017; McIlhattan et al. 2017) have found that global weather and climate models also struggle to accurately simulate cloud liquid
No AR
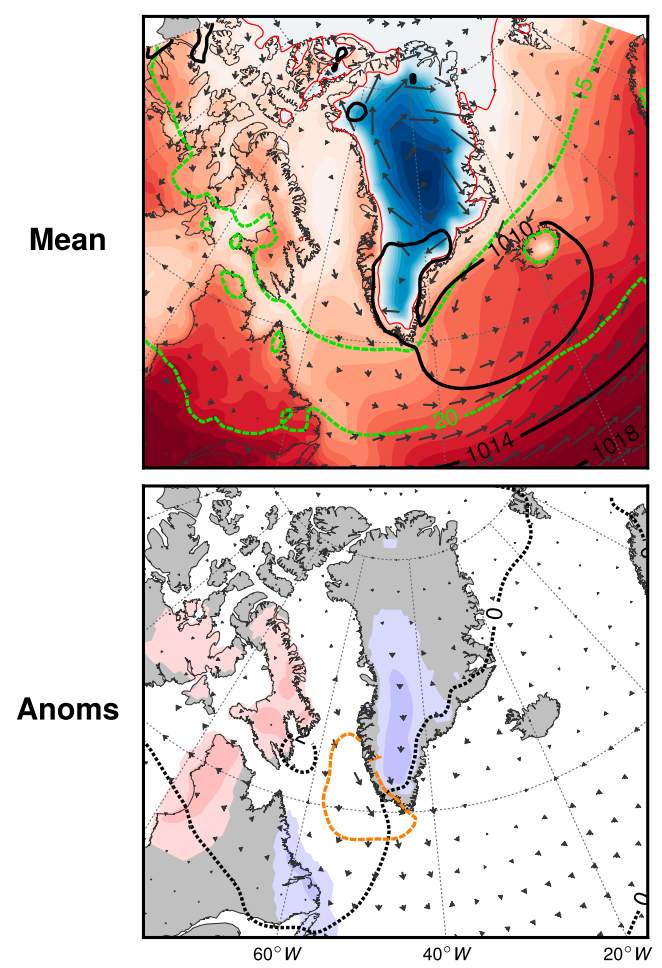

$\mathbf{A R}_{90+}$
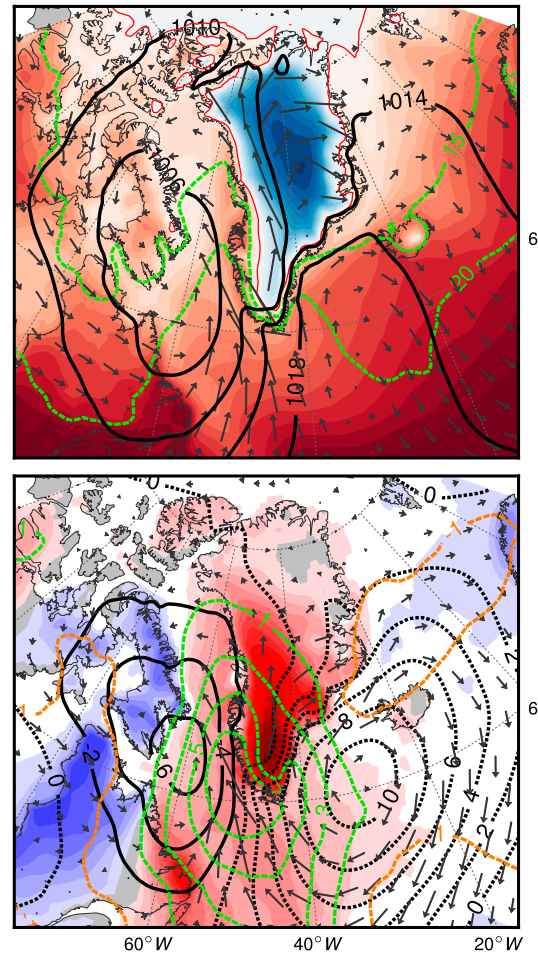

Basin 6

$$
\begin{array}{r}
\text { Mean } \\
-\quad \text { MSLP } \\
(\mathrm{hPa})
\end{array}
$$

$60^{\circ} \mathrm{N}$

Mean

PWAT

$\left(\mathrm{kg} \mathrm{m}^{-2}\right)$

MSLP -

- anoms

$(\mathrm{hPa})$

MSLP +

...... anoms

$(\mathrm{hPa})$

$60^{\circ} \mathrm{N}$

PWAT +

---- anoms

$\left(\mathrm{kg} \mathrm{m}^{-2}\right)$

PWAT -

--.=. anoms

$\left(\mathrm{kg} \mathrm{m}^{-2}\right)$
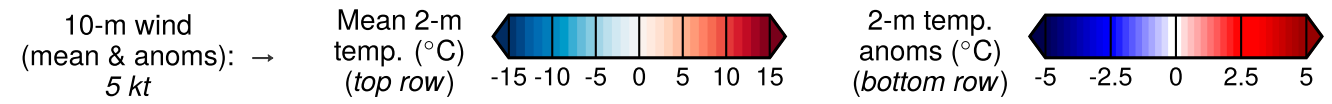

FIG. 7. Synoptic composite mean and anomaly maps of near-surface conditions from MERRA-2 on no AR and $\mathrm{AR}_{90+}$ days in basin 6. Variables mapped are mean sea level pressure (MSLP), 10-m wind, 2-m temperature, and precipitable water (PWAT). 

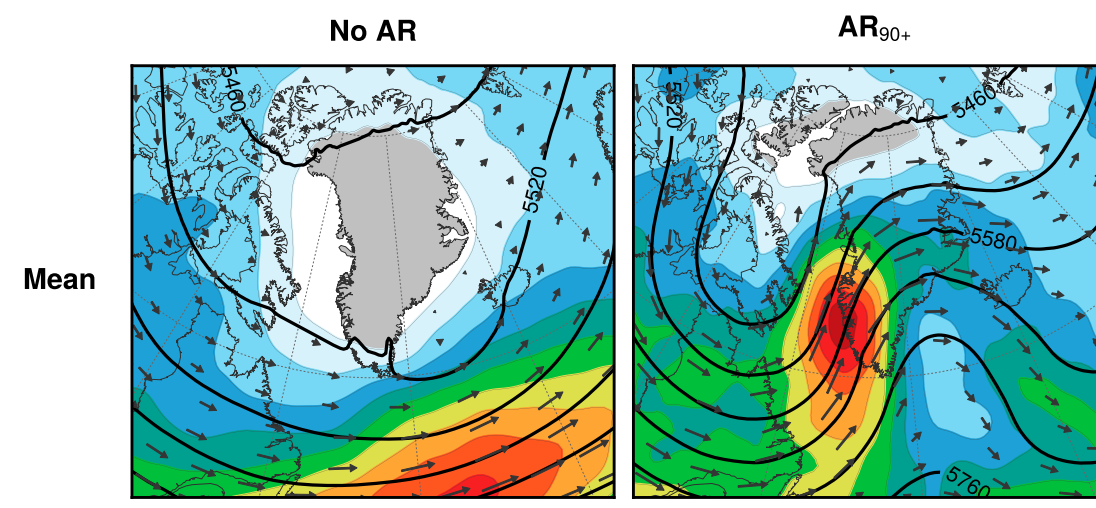

\section{Basin 6}
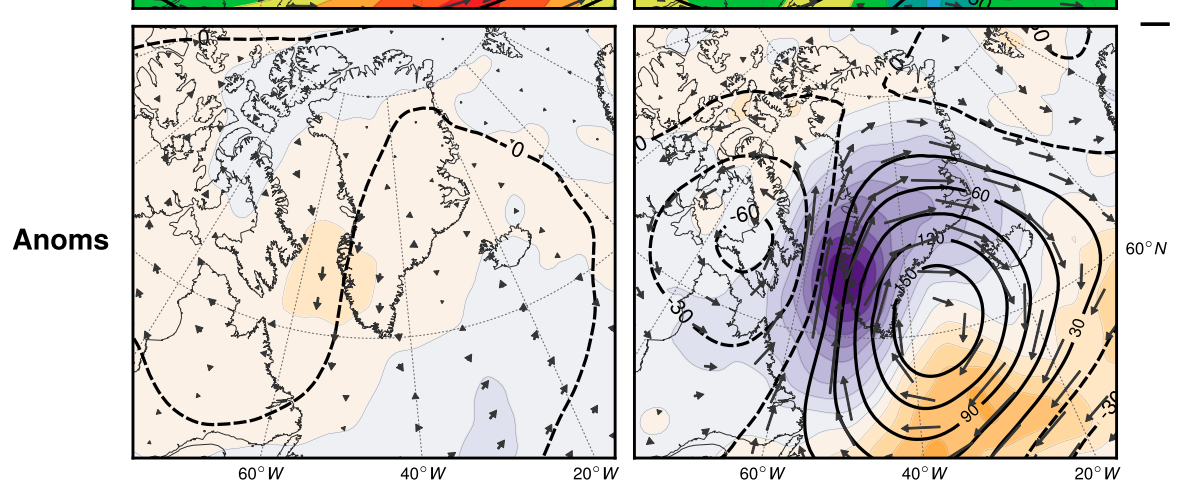

500-hPa

hgt. mean /

anoms (m)

Mean 500-hPa wind speed (kt) (top row)

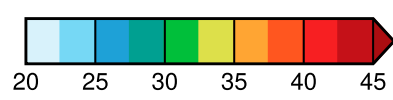

Mean 500-hPa wind speed anoms (kt) (bottom row)

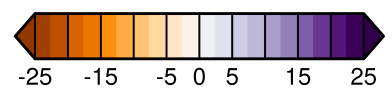

FIG. 8. As in Fig. 7, but for midtropospheric $(500 \mathrm{hPa})$ variables: geopotential height and wind speed.

water in the Arctic. ERA5 appears to slightly underestimate IWP in most areas, while MERRA-2 reproduces the magnitude and spatial pattern of IWP well (Fig. 6). These discrepancies between MAR and ERA5/MERRA2 are also evident for $\mathrm{AR}_{90+}$ events impacting basin 8 (Fig. S5, Table S4).

\section{c. Atmospheric forcing of surface energy balance and cloud properties during AR events}

On $\mathrm{AR}_{90+}$ days in basin 6 (southwest Greenland), the synoptic-scale atmospheric circulation in the lower troposphere features an anomalous area of low pressure over the Labrador Sea, Davis Strait, and Baffin Island (Fig. 7). Off the southeast coast of Greenland, the seasonally weak Icelandic low appears as a broad closed MSLP contour on basin 6 no AR days, but is replaced by an anomalous anticyclone on $\mathrm{AR}_{90+}$ days. The combination of low pressure to the west of Greenland and high pressure to the east generates southerly advection of anomalously warm, moist air over western Greenland on basin $6 \mathrm{AR}_{90+}$ days, a pattern that has also been shown to enhance snowfall from liquid-containing clouds in the western Greenland accumulation zone and at Summit Station (Pettersen et al. 2018; Mcllhattan et al. 2019). In the middle troposphere (Fig. 8), a trough of low pressure is located over northern Baffin Bay and Baffin Island on basin $6 \mathrm{AR}_{90+}$ days, with an anomalous ridge of high pressure centered off the southeast coast of Greenland and extending across southern and eastern Greenland. This trough-ridge couplet is accompanied by a northward deviation of the jet stream from its climatological position over the North Atlantic, with 500-hPa wind speeds maximized over southwest Greenland. During basin 8 $\mathrm{AR}_{90+}$ events (Figs. S8 and S9) these lower- and middletropospheric features are displaced to the northwest [resembling a pattern of recurring cyclone tracks over Baffin Bay identified by Chen et al. (1997)], with anomalous middle-tropospheric ridging extending over all of Greenland.

Vertical cross sections of wind fields and thermal variables over the K-transect region (Figs. 9 and 10) and across northern Greenland (Figs. 11 and 12) at 1800 UTC provide further insight into the surface-atmosphere interactions producing enhanced turbulent heat fluxes on $\mathrm{AR}_{90+}$ days. Climatologically, the wind field over the GrIS is katabatic, with negatively buoyant downslope flow forced by cooling of the near-surface atmosphere over the ice sheet and maximized over steeply sloping terrain (van den Broeke 

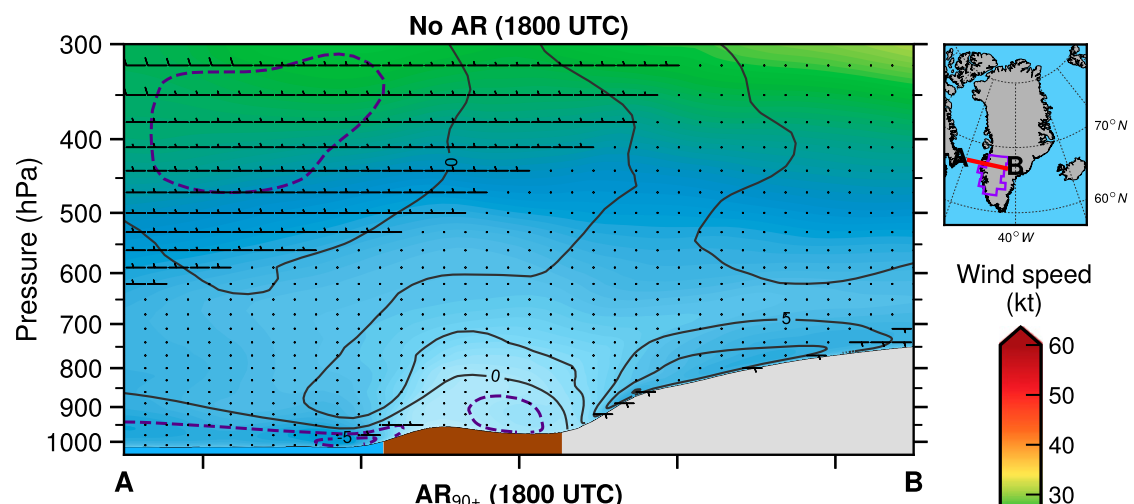

Wind speed

(kt)
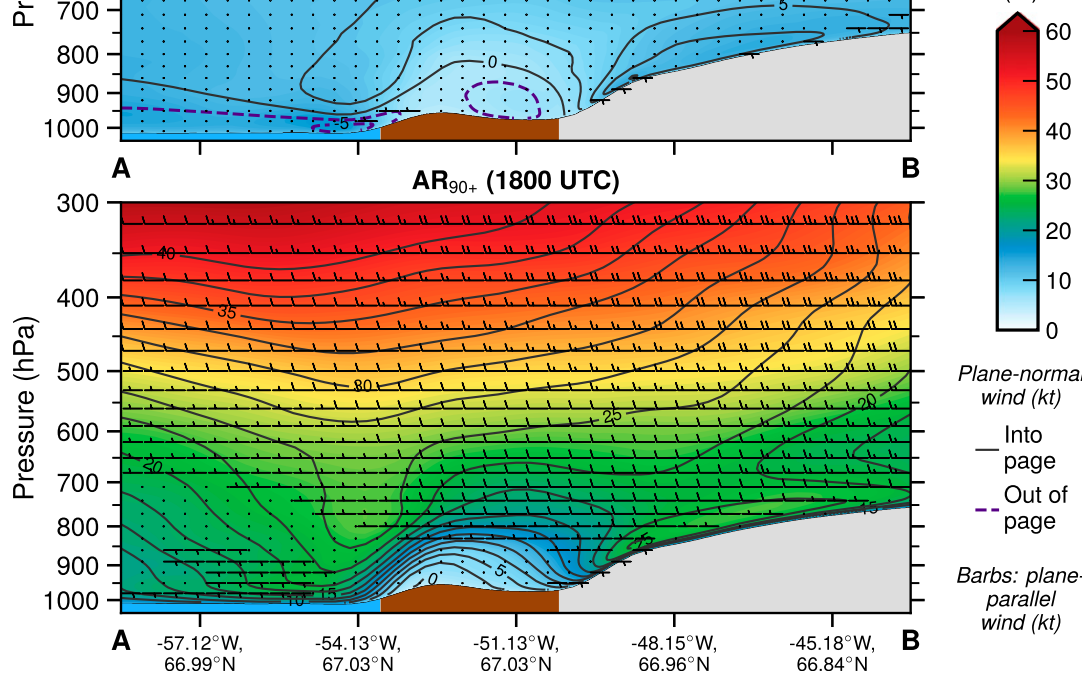

Plane-normal wind ( $k t)$

Into page

Out of

page

Barbs: plane-

parallel wind $(k t)$

FIG. 9. Vertical cross sections of ERA5 wind speed (filled), magnitude of the wind component into and out of the cross section (solid and dashed contours), and magnitude of planeparallel wind component (barbs) along a transect extending from Davis Strait inland through the K-transect region of basin 6. Cross sections are composites of conditions at 1800 UTC on (top) no $\mathrm{AR}$ days and (bottom) $\mathrm{AR}_{90+}$ days. Inset map shows location of transect from point A to point B. Below-surface areas are filled according to surface type: ocean (blue), ice-free land (brown), and ice sheet (light gray).

et al. 1994; Parish and Bromwich 1989). The katabatic wind is typically weakest on summer afternoons, as the ice sheet surface temperature is higher than in other seasons (and limited to $0^{\circ} \mathrm{C}$ during surface melt), reducing the thermal gradient between the near-surface katabatic layer and the free atmosphere during synoptically quiescent conditions (van Angelen et al. 2011; Moore et al. 2013). The relative weakness of climatological summer katabatic winds can be seen in the 1800 UTC "no AR" wind cross section over the K-transect (Fig. 9; compare to stronger 0600 UTC katabatic winds in Fig. S10).

On $\mathrm{AR}_{90+}$ days, in contrast, warm air advection results in above-freezing temperatures just above the ice sheet surface that extend much farther inland and to higher altitudes compared with no AR conditions (Fig. 10). This increases the local-scale temperature deficit of dense, nearsurface air over the ice sheet relative to the surrounding atmosphere, resulting in enhanced gravitational wind forcing that is maximized over steep terrain. Further, there is a strong synoptic-scale pressure gradient that contributes to the wind forcing on $\mathrm{AR}_{90+}$ days. This can be seen in the large-scale synoptic composite maps (Figs. 7 and 8), and more subtly appears in the sloping of potential temperature and geopotential height contours from the ridge over Greenland to the trough over Baffin Bay in the $\mathrm{AR}_{90+}$ cross section (Fig. 10). This large-scale pressure gradient generates what previous studies have termed a "barrier jet" or "Greenland plateau jet" in the free atmosphere perpendicular to the terrain gradient of the western GrIS, which is coupled to the near-surface katabatic layer through positive vertical wind shear above the boundary layer (van den Broeke and Gallée 1996; Moore et al. 2013). The coupling of these locally and synoptically forced winds results in mixing of warm air downward into the boundary layer and strong sensible heat flux into the ice sheet surface, a phenomenon that previous studies have also noted during periods of strong synoptic forcing (Meesters 1994; van den Broeke and Gallée 1996; Heinemann and Falk 2002). Although we focus on afternoon (1800 UTC) conditions, we also note that nighttime (0600 UTC) wind speeds are higher (Fig. S10) on $\mathrm{AR}_{90+}$ days compared to no AR days and the strength of the 


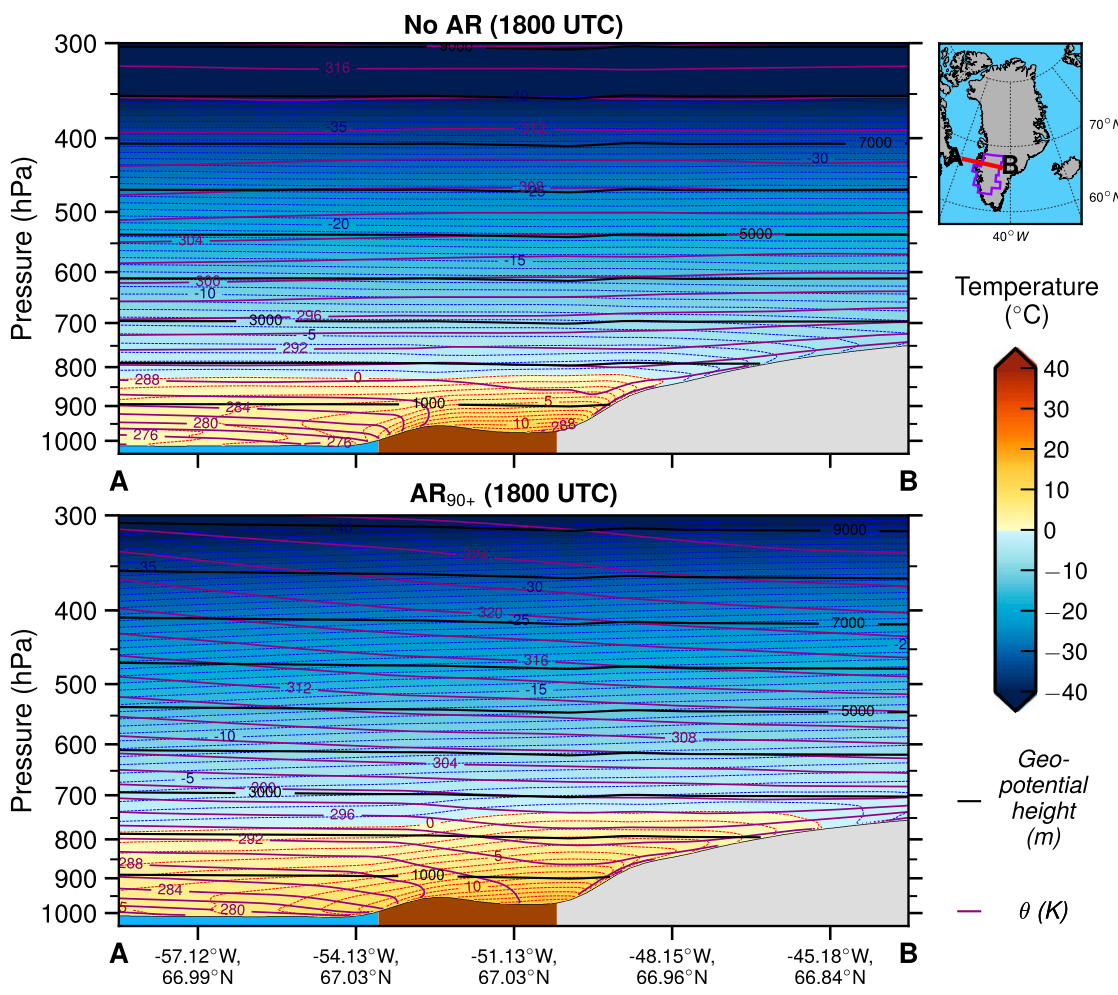

FIG. 10. As in Fig. 9, but the cross section shows thermal fields (temperature, potential temperature $\theta$, and geopotential height) in the $\mathrm{K}$-transect region.

nighttime (0600 UTC) inversion is reduced (Fig. S11), indicating strengthened turbulent heat fluxes on $\mathrm{AR}_{90+}$ days even with little to no incoming solar radiation.

During basin $8 \mathrm{AR}_{90+}$ events, the afternoon wind and thermal cross sections (Figs. 11 and 12) resemble the $\mathrm{K}$-transect cross sections in the AR landfall area of northwest Greenland, although katabatic winds are stronger than over the K-transect on no AR days due to the greater surface slope angle. Over northeast Greenland, the thermal cross sections (Fig. 12) show above-freezing temperatures extending to much higher altitudes over the ice sheet on $\mathrm{AR}_{90+}$ compared to no AR afternoons, and closely packed potential temperature contours indicate a strengthening of the temperature inversion on basin $8 \mathrm{AR}_{90+}$ days. These features are produced by downslope flow and adiabatic warming above the near-surface katabatic layer, which increases the temperature deficit of the katabatic layer and strengthens wind speeds, particularly in the area immediately upslope from the steepest topography (Fig. 11). The synoptic pressure gradient is weaker than in northwest Greenland and the vertical distance between the upperlevel jet and the near-surface katabatic wind maximum is $100-200 \mathrm{hPa}$ greater than in northwest Greenland, and thus local-scale katabatic and thermal forcing likely plays the dominant role in driving enhanced wind speeds in northeast
Greenland. This enhanced katabatic wind entrains adiabatically warmed air from above the katabatic layer and mixes it toward the surface, leading to the enhanced SHF described in section 3 a.

Additional insight into the drivers of anomalous energy fluxes during $\mathrm{AR}_{90+}$ events is provided by cross sections of moisture and vertical velocity fields (Figs. 13 and 14). Over the K-transect region, ERA5 shows specific humidity values that are on the order of $5-20 \mathrm{~g} \mathrm{~kg}^{-1}$ higher throughout the lower and middle troposphere on $\mathrm{AR}_{90+}$ compared to no AR days (Fig. 13). This anomalous moisture content, along with widespread upward motion above the boundary layer, results in extensive cloud formation in the vicinity of AR landfall (see Fig. 6, Figs. S6 and S7) that produces negative $\mathrm{SW}_{\text {net }}$ and positive $\mathrm{LW}_{\text {net }}$ anomalies over the K-transect. Combined with the strong wind speeds detailed above, the high atmospheric water vapor content also results in increased latent heat flux. Over northeast Greenland during basin $8 \mathrm{AR}_{90+}$ events, downward vertical motion extends through a deeper layer of the troposphere than normal, with especially intense downslope flow along the steepest slopes near the ice sheet edge (Fig. 14). This foehn effect warms the air above the boundary layer and water vapor content decreases through precipitation as air passes over the GrIS terrain barrier, 


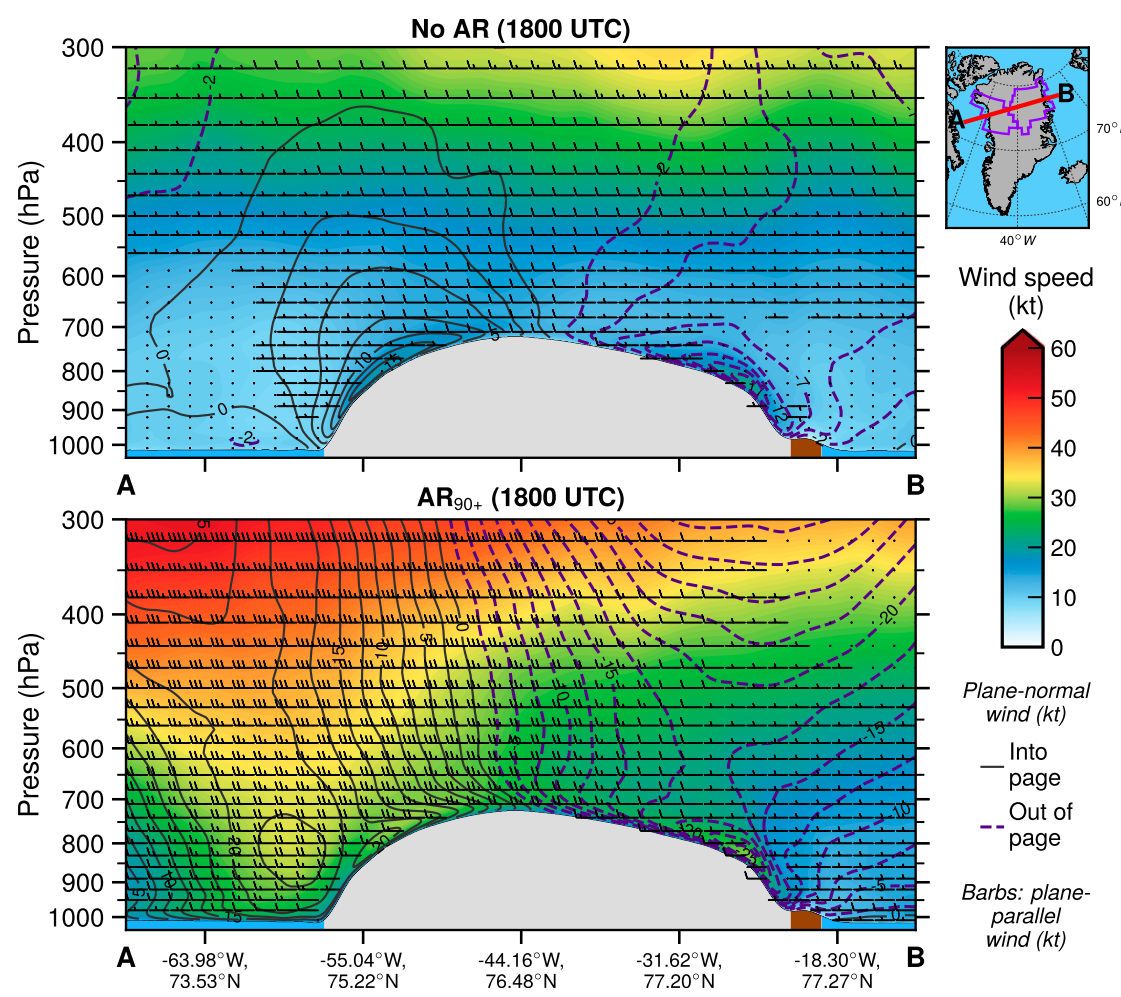

FIG. 11. As in Fig. 9, but the cross section extends across Greenland from basin 8 through basin 2 for basin 8 no $A R$ and $\mathrm{AR}_{90+}$ days.

resulting in low relative humidity throughout the troposphere over the northeast GrIS. This combination of drying, clearing, warming, enhanced downward motion, and increased katabatic wind speeds explains the positive $\mathrm{SW}_{\text {net }}$ and negative $\mathrm{LW}_{\text {net }}$ anomalies, positive SHF anomalies, and negative LHF anomalies over the northeastern GrIS ablation zone on basin $8 \mathrm{AR}_{90+}$ days.

\section{Discussion and conclusions}

Through analysis of the surface energy balance, cloud properties, and synoptic- to local-scale atmospheric conditions during AR events, we have elucidated the atmospheric forcing and surface-atmosphere interactions that generate enhanced GrIS surface melt when a strong AR impacts western Greenland during summer. In the immediate vicinity of the AR landfall, $\mathrm{AR}_{90+}$ days are characterized by cloudy, moist, warm, and windy atmospheric conditions over the ice sheet. Compared with no AR conditions, cloud cover increases by $30 \%-40 \%$, precipitable water increases by $3-7 \mathrm{~kg} \mathrm{~m}^{-2}, 2-\mathrm{m}$ temperatures increase by $3^{\circ}-5^{\circ} \mathrm{C}$, and near-surface wind speeds increase by $3-5 \mathrm{~m} \mathrm{~s}^{-1}$ on a mean $\mathrm{AR}_{90+}$ day. The presence of clouds-which are produced by enhanced lower- and middle-tropospheric vertical motion acting on anomalous amounts of water vapor-decreases $\mathrm{SW}_{\text {net }}$ and increases $\mathrm{LW}_{\text {net }}$. As these radiative anomalies partially cancel one another, turbulent fluxes of sensible and (to a lesser extent) latent heat become the dominant terms of the SEB across the ablation zone of the GrIS, where enhanced wind speeds entrain warm air into the near-ice air layer and where surface roughness is greatest. This anomalously strong barrier wind is driven by a combination of an increased synoptic-scale pressure gradient and the intensified local-scale thermal contrast between the cool near-ice atmospheric layer and the surrounding atmosphere as it is heated through warm air advection. At higher elevations, turbulent fluxes are reduced in the AR "landfall" basin and more modest melt energy anomalies are primarily forced by the radiative effects of clouds.

In contrast to the cloudy melt regime in the vicinity of AR landfall, during strong AR events affecting northwest Greenland, enhanced melt energy is also produced in the northeast GrIS ablation zone with dry, clear, and windy conditions due to a foehn effect. Anomalously clear skies resulting from downward air parcel motion and drying lead to enhanced $\mathrm{SW}_{\text {net }}$ over this area, while adiabatic warming above the near-ice layer leads to increased katabatic wind speeds and SHF. Our finding of 


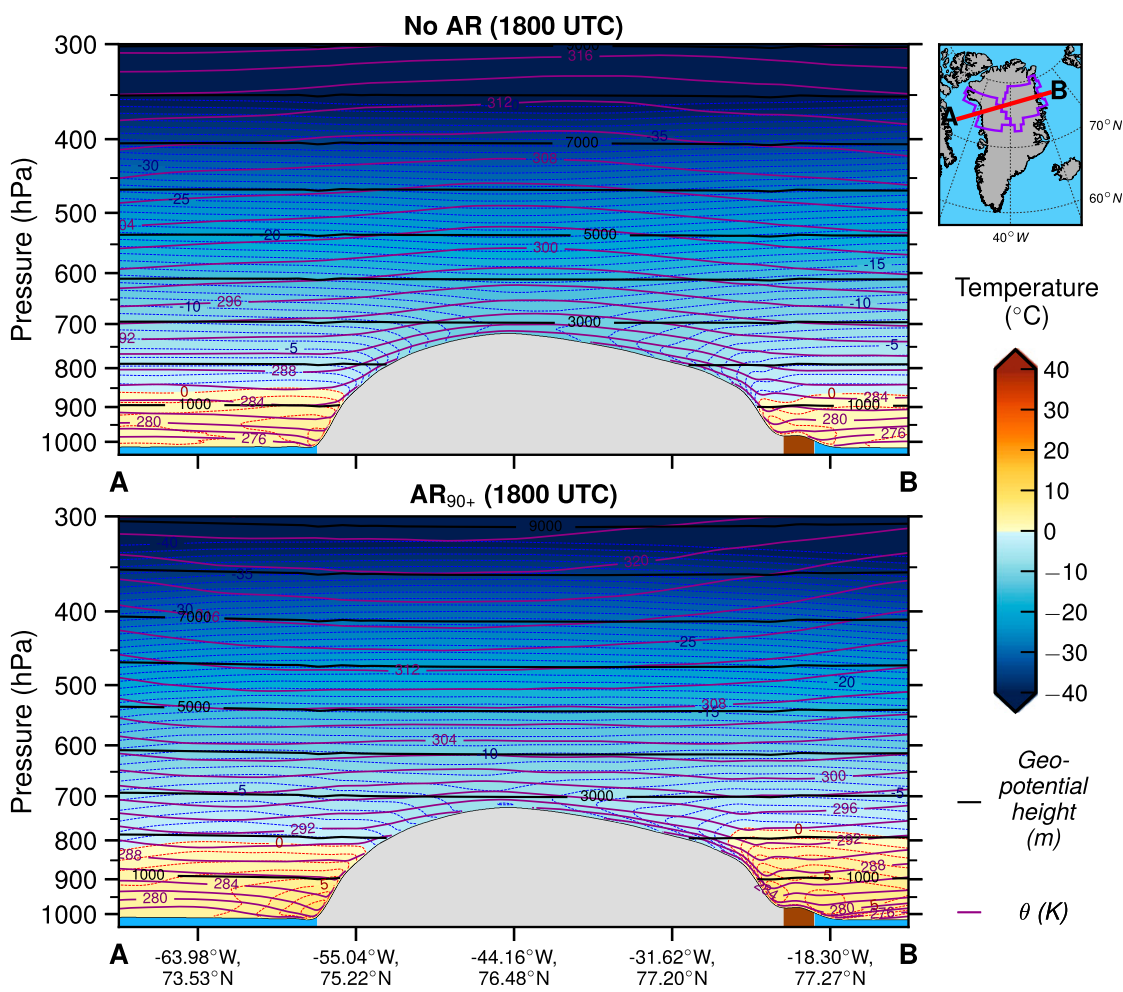

FIG. 12. As in Fig. 10, but the cross section extends across Greenland from basin 8 through basin 2 for basin 8 no $A R$ and $\mathrm{AR}_{90+}$ days.

melt forced by downslope flow in northeast Greenland during northwest Greenland ARs agrees with the results of Cullather and Nowicki (2018), Välisuo et al. (2018), and Noël et al. (2019), and together our results suggest that foehn conditions may be responsible for the largest melt events in this region. A similar contrast between cloudy and clear conditions windward and leeward of an orographic barrier during AR events has been documented in western Antarctica (Wille et al. 2019).

We find that the model, reanalysis, satellite, and observational data sources employed in this study agree on the qualitative changes in SEB terms, fractional cloud cover, and atmospheric conditions that occur during strong summer AR events. However, there is considerable disagreement among these datasets regarding the values of SEB terms as well as cloud liquid and ice water quantities. MAR generally performs better than ERA5 and MERRA-2 in reproducing SEB terms, using measured radiative fluxes and derived turbulent fluxes from PROMICE stations as reference data. However, it still exhibits a negative $\mathrm{SW}_{\text {net }}$ bias and positive LHF bias in the western Greenland ablation zone, particularly during $\mathrm{AR}_{90+}$ events. Additionally, based on the results of previous studies (Fausto et al. 2016b; Hermann et al. 2018), it is possible that SHF in the ablation zone during $\mathrm{AR}_{90+}$ events is substantially greater than either the values simulated by MAR or those derived from PROMICE observations. MAR appears to severely underestimate cloud liquid amounts by overestimating cloud ice phase over the GrIS regardless of AR conditions. ERA5 and MERRA-2 perform better than MAR when compared to hybrid RACMOsatellite cloud data and Summit Station LWP retrievals, but these reanalyses still have too little cloud liquid on average over most of the GrIS during $\mathrm{AR}_{90+}$ events, suggesting the representation of liquid clouds versus ice clouds should be improved in the models, particularly in MAR.

Our results may provide a pathway toward reconciling contrasting perspectives on the role of clouds in GrIS melt. A number of studies (e.g., Bennartz et al. 2013; Van Tricht et al. 2016; Gallagher et al. 2018) have found that clouds act to warm the GrIS surface. The warming effect of clouds has been shown to be stronger in the accumulation zone than the ablation zone (Niwano et al. 2019; W. Wang et al. 2019). In contrast, Hofer et al. (2017) found a decreasing trend in summer cloud cover over much of Greenland during 19952009, and calculated that decreased cloud cover mainly drove the increasing GrIS melt trend over this time period through enhanced $\mathrm{SW}_{\text {net }}$ and melt-albedo feedback. In this study, we show that intense GrIS melt occurs under cloudy conditions in the vicinity of AR landfall, but melt also 


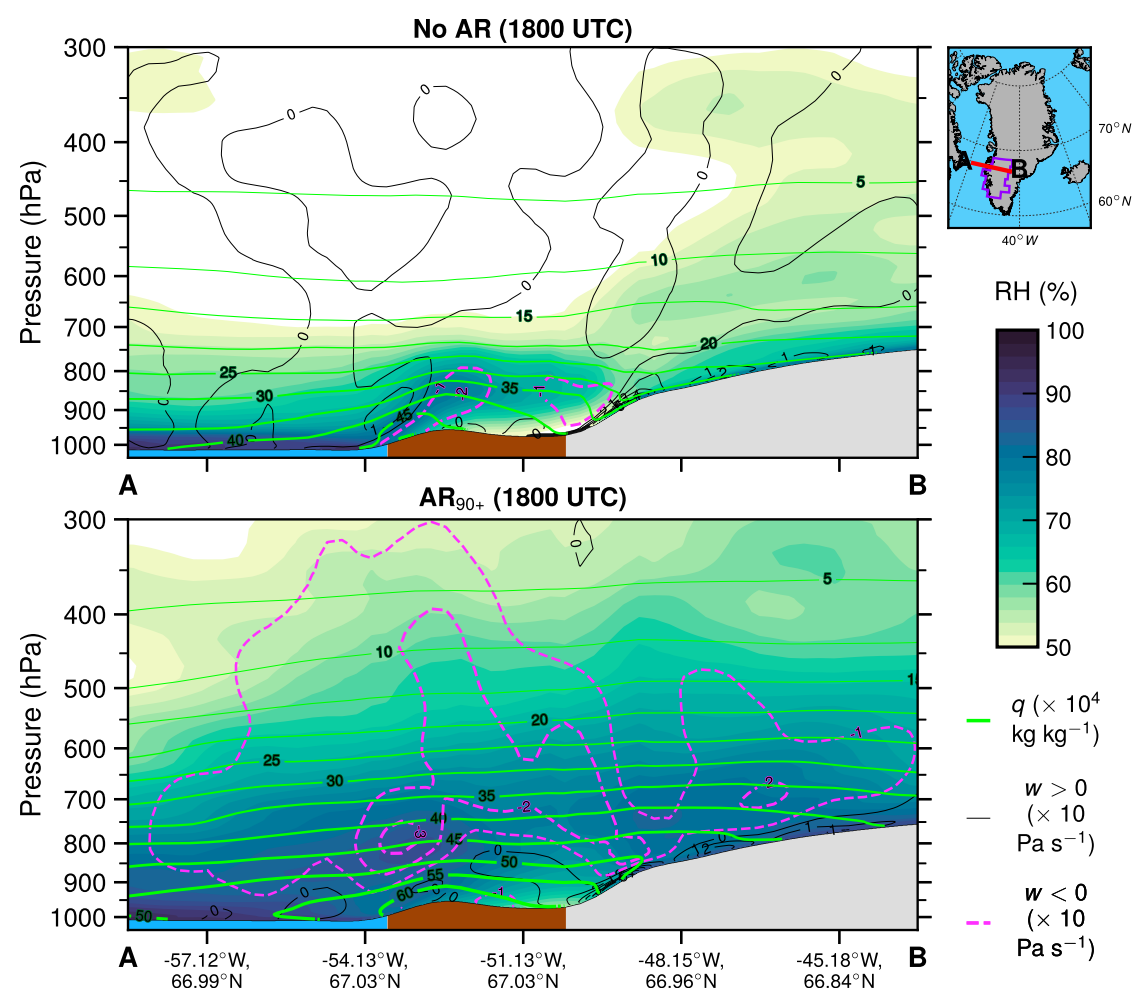

FIG. 13. As in Figs. 9 and 10, but the cross section shows moisture fields (specific humidity $q$ and relative humidity) along with upward and downward vertical velocity ( $w<0$ and $w>0$, respectively) in the K-transect region.

occurs under anomalously clear skies in eastern Greenland during strong northwest Greenland AR events. Moreover, ARs often occur along the upstream flank of a blocking anticyclone (Liu and Barnes 2015; Baggett et al. 2016; Mundhenk et al. 2016b; Bozkurt et al. 2018), and in many cases latent heat release in the rising warm conveyer belt associated with an AR helps to amplify the blocking anticyclone (McLeod and Mote 2015; Pfahl et al. 2015; Grams and Archambault 2016). Greenland blocking events often last for several days or even weeks (Davini et al. 2012; Hanna et al. 2018b; S. Wang et al. 2019), lingering for a much longer period of time than a typical AR event.

Therefore we propose a conceptual model whereby a strong AR produces an intense initial melt surge-often through simultaneous cloudy and clear melt regimes, varying spatially across the GrIS-and forces a decrease in GrIS albedo. If the AR event is accompanied and/or followed in subsequent days by Greenland blocking conditions and decreased cloud cover, melt-albedo feedback triggered by the AR will contribute to enhanced melt through absorption of solar radiation. We note that a few ephemeral strong AR events interspersed with longerlived blocking conditions during a given summer could manifest as an overall anomalously low amount of seasonally averaged cloud cover, and that the decreasing cloud cover trend found by Hofer et al. (2017) overlaps temporally with an increasing trend in the magnitude of seasonally summed summer moisture transport to western Greenland (Mattingly et al. 2016; M18). We hypothesize that both cloudy and clear sky atmospheric regimes synergistically combine to force anomalous GrIS melt during at least some summers, as also suggested by Oltmanns et al. (2019). Future studies should investigate this hypothesis by examining the evolution of GrIS albedo and SEB prior to, during, and after strong AR and blocking events during individual seasons. It is also possible that AR landfalls in other areas of Greenland may force melt in remote regions through a foehn effect, and future studies are planned to investigate this phenomenon in more detail. For example, a series of ARs affected eastern Greenland during April and May 2019, at the same time as unusual early season melt was observed in the western GrIS ablation zone. Finally, the effects of ARs on GrIS SEB should be analyzed during other seasons to determine similarities and differences between the effects of summer and nonsummer AR events, including possible preconditioning of warm season melt by nonsummer ARs. 


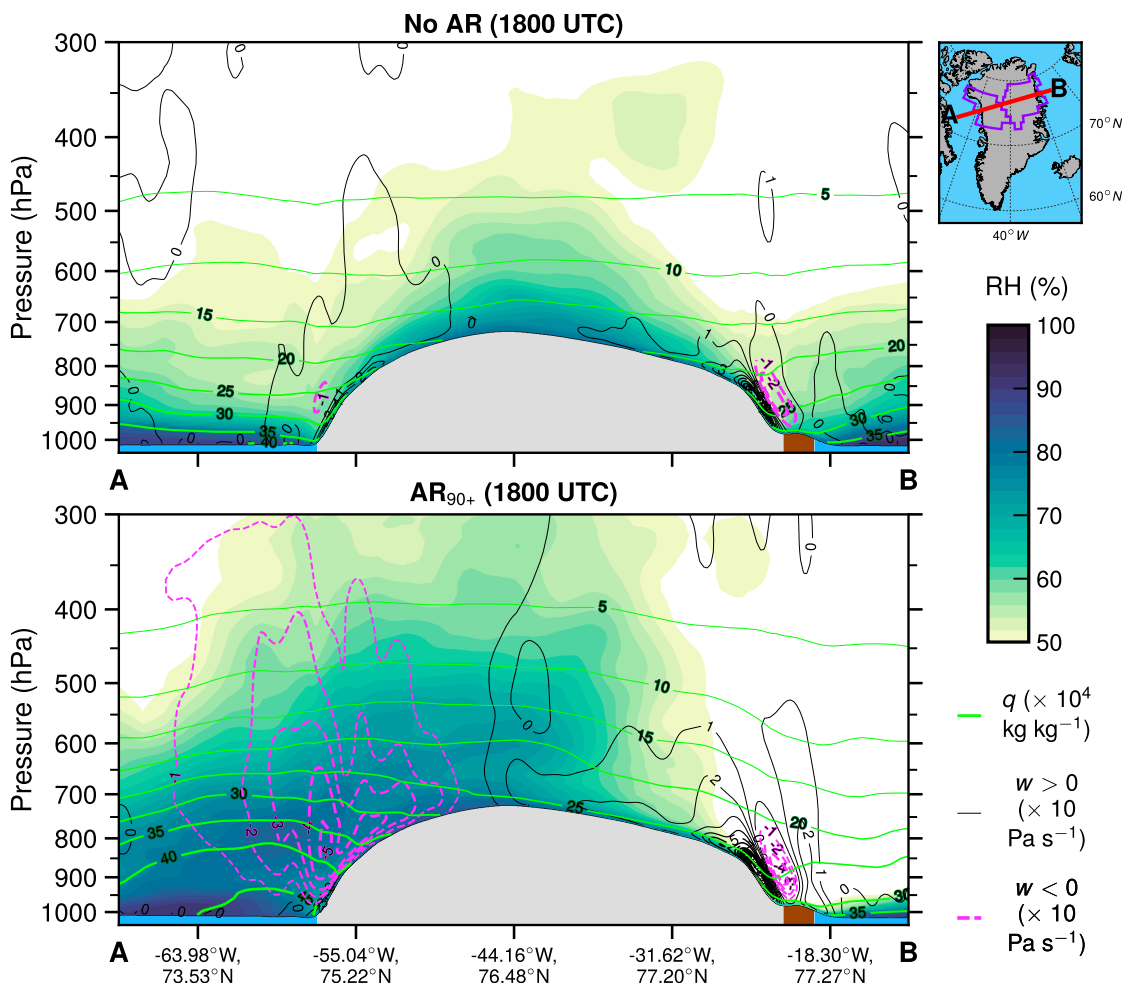

FIG. 14. As in Fig. 13, but the cross section extends across Greenland from basin 8 through basin 2 for basin 8 no $A R$ and $\mathrm{AR}_{90+}$ days.

Acknowledgments. The authors thank Stefan Hofer for assistance with the MAR cloud data. K. S. Mattingly was supported by a NASA Earth and Space Science Fellowship (NASA Grant NNX16A022H). D. van As and R. S. Fausto were supported by the Programme for Monitoring of the Greenland Ice Sheet (PROMICE) of the Geological Survey of Denmark and Greenland (GEUS), funded by the Danish Ministry of Climate, Energy and Utilities. C. Pettersen was supported by NSF Grants 1304544 and 1801318. Computational resources for MAR simulations were provided by the Consortium des Équipements de Calcul Intensif (CÉCI), funded by the Fonds de la Recherche Scientifique de Belgique (F.R.S.FNRS) under grant 2.5020.11 and the Tier-1 supercomputer (Zenobe) of the Fédération Wallonie Bruxelles infrastructure funded by the Walloon Region under Grant Agreement 1117545. ERA5 data are available from the Copernicus Climate Change Service Climate Data Store (https://cds.climate. copernicus.eu) and MERRA-2 data are available from the NASA Goddard Earth Sciences Data and Information Services Center (https://disc.gsfc.nasa.gov/). MAR data are available at ftp://climato.be/fettweis/MARv3.9/Greenland/ ERAint_1979-2018_7_5km/. Data from the Programme for Monitoring of the Greenland Ice Sheet (PROMICE) and the Greenland Analogue Project (GAP) are provided by GEUS at http://www.promice.dk. Summit Station LWP data are available from the NOAA Earth System Research Laboratory's Physical Sciences Division (PSD): https://www.esrl.noaa.gov/psd/arctic/observatories/ summit/. Hybrid RACMO-satellite cloud data are available upon request from Kristof Van Tricht and Stef Lhermitte.

\section{APPENDIX}

\section{Odds Ratio Method for Classifying AR Intensity}

To distinguish between "normal" and "strong" AR events, we analyze the frequency of anomalously warm, windy, and moist conditions at the four low-elevation PROMICE stations in basins 6 and 8. We define extreme warm, moist, windy "heat wave" days (Hermann et al. 2018) at KAN_L, NUK_L, and UPE_L as those with any hourly observation of 2-m temperature $\geq 5^{\circ} \mathrm{C}$ and specific humidity $\geq 3 \mathrm{~g} \mathrm{~kg}^{-1}$, simultaneous with wind speeds $\geq 8 \mathrm{~m} \mathrm{~s}^{-1}$. The temperature threshold is $2^{\circ} \mathrm{C}$ at THU_L.

We compare the probability of heat wave events on no AR days to days when an AR of any intensity occurred. We further analyze whether more intense ARs are more likely to result in heat wave events by comparing the 


\section{- OR (1\%-ile IVT PR intervals)}
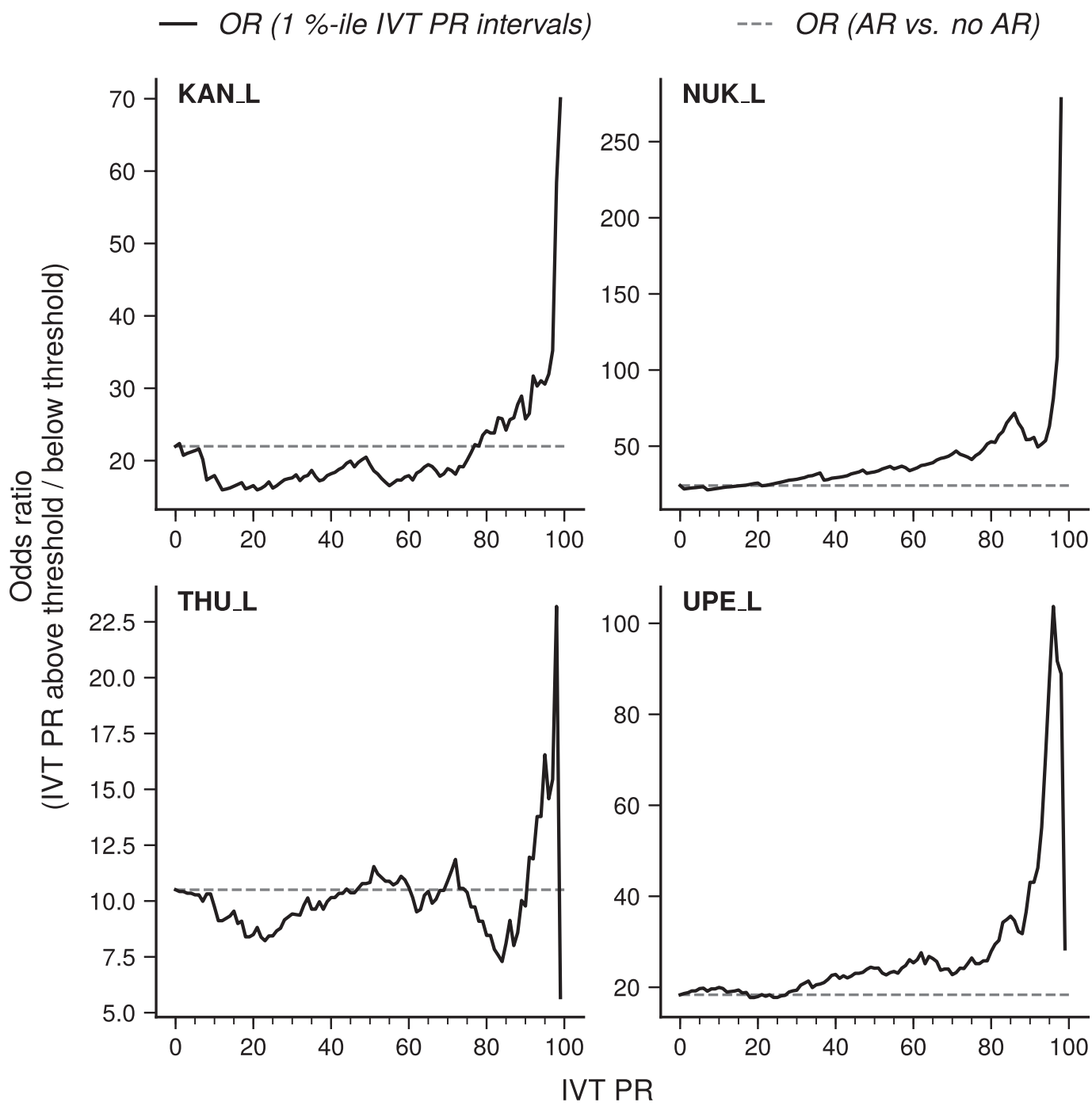

FIG. A1. Odds ratio of heat wave events across IVT percentiles (solid black lines) at four low-elevation PROMICE stations in basins 6 and 8: KAN_L, NUK_L, THU_L, and UPE_L. Also plotted is the odds ratio of heat wave events on days with an AR of any intensity vs no AR days (gray dashed lines).

probability of these events to their probability on no AR days across one-percentile intervals of AR IVT. These probability comparisons are performed by calculating the odds ratio (Miller and Mote 2018):

$$
\mathrm{OR}=\frac{A / C}{B / D}
$$

where $A / C$ is the ratio of heat wave days to non-heat wave days when an $\mathrm{AR}$ affects the given basin, and $B / D$ is the same ratio when an AR does not affect the given basin. In calculating the odds ratio across IVT percentile rank thresholds, the condition to be met is that maximum IVT exceeds the given percentile rank of the basin-specific distribution. For example, the odds ratio at the 90th percentile in Fig. A1 shows the ratio of heat wave days to non-heat wave days when maximum IVT within any AR over the basin exceeds the 90th percentile, divided by the same ratio when there is no AR or an AR with <90th percentile IVT.

Figure A1 shows that the odds of a heat wave are 10-25 times higher on AR days compared to no AR days at the four PROMICE stations. Odds ratios are steady or slowly increase across IVT percentiles 0 through 90 , then sharply increase around the $90-95$ th percentiles. We thus chose the 90th percentile of AR IVT to distinguish between normal ARs $\left(\mathrm{AR}_{<90}\right)$ and strong $\mathrm{ARs}\left(\mathrm{AR}_{90+}\right)$.

\section{REFERENCES}

Agosta, C., and Coauthors, 2019: Estimation of the Antarctic surface mass balance using the regional climate model MAR (1979-2015) and identification of dominant processes. 
Cryosphere, 13, 281-296, https://doi.org/10.5194/tc-13281-2019.

Ahlstrøm, A. P., D. Petersen, P. L. Langen, M. Citterio, and J. E. Box, 2017: Abrupt shift in the observed runoff from the southwestern Greenland ice sheet. Sci. Adv., 3, e1701169, https://doi.org/10.1126/sciadv.1701169.

Alexander, P. M., M. Tedesco, X. Fettweis, R. S. W. van de Wal, C. J. P. P. Smeets, and M. R. van den Broeke, 2014: Assessing spatio-temporal variability and trends in modelled and measured Greenland Ice Sheet albedo (2000-2013). Cryosphere, $\mathbf{8}$, 2293-2312, https://doi.org/10.5194/tc-8-2293-2014.

- A. N. LeGrande, E. Fischer, M. Tedesco, X. Fettweis, M. Kelley, S. M. J. Nowicki, and G. A. Schmidt, 2019: Simulated Greenland surface mass balance in the GISS ModelE2 GCM: Role of the ice sheet surface. J. Geophys. Res. Earth, 124, 750-765, https://doi.org/10.1029/2018JF004772.

Auger, J. D., S. D. Birkel, K. A. Maasch, P. A. Mayewski, and K. C. Schuenemann, 2017: Examination of precipitation variability in southern Greenland. J. Geophys. Res. Atmos., 122, 62026216, https://doi.org/10.1002/2016JD026377.

Baggett, C., S. Lee, and S. Feldstein, 2016: An investigation of the presence of atmospheric rivers over the North Pacific during planetary-scale wave life cycles and their role in Arctic warming. J. Atmos. Sci., 73, 4329-4347, https://doi.org/10.1175/ JAS-D-16-0033.1.

Ballinger, T. J., and Coauthors, 2019: Greenland Ice Sheet lateseason melt: Investigating multiscale drivers of K-transect events. Cryosphere, 13, 2241-2257, https://doi.org/10.5194/tc13-2241-2019.

Bamber, J. L., R. M. Westaway, B. Marzeion, and B. Wouters, 2018: The land ice contribution to sea level during the satellite era. Environ. Res. Lett., 13, 063008, https://doi.org/10.1088/ 1748-9326/aac2f0.

Bennartz, R., and Coauthors, 2013: July 2012 Greenland melt extent enhanced by low-level liquid clouds. Nature, 496, 83-86, https://doi.org/10.1038/nature12002.

Berdahl, M., and Coauthors, 2018: Southeast Greenland winter precipitation strongly linked to the Icelandic low position J. Climate, 31, 4483-4500, https://doi.org/10.1175/JCLI-D-170622.1.

Bonne, J.-L., and Coauthors, 2015: The summer 2012 Greenland heat wave: In situ and remote sensing observations of water vapor isotopic composition during an atmospheric river event. J. Geophys. Res. Atmos., 120, 2970-2989, https://doi.org/ 10.1002/2014JD022602.

Box, J. E., X. Fettweis, J. C. Stroeve, M. Tedesco, D. K. Hall, and K. Steffen, 2012: Greenland ice sheet albedo feedback: Thermodynamics and atmospheric drivers. Cryosphere, 6, 821-839, https://doi.org/10.5194/tc-6-821-2012.

Bozkurt, D., R. Rondanelli, J. C. Marín, and R. Garreaud, 2018 Foehn event triggered by an atmospheric river underlies record-setting temperature along continental Antarctica. J. Geophys. Res. Atmos., 123, 3871-3892, https://doi.org/ 10.1002/2017JD027796.

Braithwaite, R. J., and O. B. Olesen, 1990: Response of the energy balance on the margin of the Greenland Ice Sheet to temperature changes. J. Glaciol., 36, 217-221, https://doi.org/ 10.1017/S0022143000009461.

Calov, R., and Coauthors, 2018: Simulation of the future sea level contribution of Greenland with a new glacial system model Cryosphere, 12, 3097-3121, https://doi.org/10.5194/tc-12-30972018.
Charalampidis, C., and Coauthors, 2015: Changing surfaceatmosphere energy exchange and refreezing capacity of the lower accumulation area, West Greenland. Cryosphere, 9, 2163-2181, https://doi.org/10.5194/tc-9-2163-2015.

Chen, Q., D. H. Bromwich, and L. Bai, 1997: Precipitation over Greenland retrieved by a dynamic method and its relation to cyclonic activity. J. Climate, 10, 839-870, https://doi.org/ 10.1175/1520-0442(1997)010<0839:POGRBA > 2.0.CO;2.

Copernicus Climate Change Service, 2017: ERA5: Fifth generation of ECMWF atmospheric reanalyses of the global climate. Copernicus Climate Change Service Climate Data Store (CDS), accessed 9 May 2019, https://cds.climate.copernicus. eu/cdsapp\#!/home.

Cullather, R. I., and S. M. J. Nowicki, 2018: Greenland Ice Sheet surface melt and its relation to daily atmospheric conditions. J. Climate, 31, 1897-1919, https://doi.org/10.1175/JCLI-D-170447.1.

Dacre, H. F., P. A. Clark, O. Martinez-Alvarado, M. A. Stringer, and D. A. Lavers, 2015: How do atmospheric rivers form? Bull. Amer. Meteor. Soc., 96, 1243-1255, https://doi.org/ 10.1175/BAMS-D-14-00031.1.

Davini, P., C. Cagnazzo, S. Gualdi, and A. Navarra, 2012: Bidimensional diagnostics, variability, and trends of Northern Hemisphere blocking. J. Climate, 25, 6496-6509, https:// doi.org/10.1175/JCLI-D-12-00032.1.

Delhasse, A., X. Fettweis, C. Kittel, C. Amory, and C. Agosta, 2018: Brief communication: Impact of the recent atmospheric circulation change in summer on the future surface mass balance of the Greenland Ice Sheet. Cryosphere, 12, 3409-3418, https://doi.org/10.5194/tc-12-3409-2018.

, C. Kittel, C. Amory, S. Hofer, D. van As, R. S. Fausto, and X. Fettweis, 2020: Brief communication: Evaluation of the near-surface climate in ERA5 over the Greenland Ice Sheet. Cryosphere, 14, 957-965, https://doi.org/10.5194/tc-14-9572020.

De Ridder, K., and G. Schayes, 1997: The IAGL land surface model. J. Appl. Meteor., 36, 167-182, https://doi.org/10.1175/ 1520-0450(1997)036<0167:TILSM>2.0.CO;2.

— change in southern Israel. J. Appl. Meteor., 37, 1470-1485, https://doi.org/10.1175/1520-0450(1998)037<1470:LSIRCC> 2.0.CO;2.

Doyle, S. H., and Coauthors, 2015: Amplified melt and flow of the Greenland ice sheet driven by late-summer cyclonic rainfall. Nat. Geosci., 8, 647-653, https://doi.org/10.1038/ngeo2482.

Fausto, R. S., D. van As, J. E. Box, W. Colgan, and P. L. Langen, 2016a: Quantifying the surface energy fluxes in South Greenland during the 2012 high melt episodes using In-situ observations. Front. Earth Sci., 4, 82, https://doi.org/10.3389/ feart.2016.00082.

, and R. H. Mottram, 2016b: The implication of nonradiative energy fluxes dominating Greenland ice sheet exceptional ablation area surface melt in 2012. Geophys. Res. Lett., 43, 2649-2658, https://doi.org/10.1002/ 2016GL067720.

Fettweis, X., E. Hanna, C. Lang, A. Belleflamme, M. Erpicum, and H. Gallee, 2013: Brief communication: Important role of the mid-tropospheric atmospheric circulation in the recent surface melt increase over the Greenland ice sheet. Cryosphere, 7, 241-248, https://doi.org/10.5194/tc-7-241-2013.

and Coauthors, 2017: Reconstructions of the 1900-2015 Greenland ice sheet surface mass balance using the regional 
climate MAR model. Cryosphere, 11, 1015-1033, https:// doi.org/10.5194/tc-11-1015-2017.

- , and Coauthors, 2020: GrSMBMIP: Intercomparison of the modelled 1980-2012 surface mass balance over the Greenland Ice sheet. Cryosphere Discuss., https://doi.org/10.5194/tc-2019321 , in press.

Forbes, R. M., and M. Ahlgrimm, 2014: On the representation of high-latitude boundary layer mixed-phase cloud in the ECMWF global model. Mon. Wea. Rev., 142, 3425-3445, https://doi.org/10.1175/MWR-D-13-00325.1.

Franco, B., X. Fettweis, and M. Erpicum, 2013: Future projections of the Greenland ice sheet energy balance driving the surface melt. Cryosphere, 7, 1-18, https://doi.org/10.5194/tc-7-1-2013.

Gallagher, M. R., M. D. Shupe, and N. B. Miller, 2018: Impact of atmospheric circulation on temperature, clouds, and radiation at Summit Station, Greenland, with self-organizing maps. J. Climate, 31, 8895-8915, https://doi.org/10.1175/JCLI-D-170893.1.

Gallée, H., and G. Schayes, 1994: Development of a threedimensional meso- $\gamma$ primitive equation model: Katabatic winds simulation in the area of Terra Nova Bay, Antarctica. Mon. Wea. Rev., 122, 671-685, https://doi.org/10.1175/15200493(1994)122<0671:DOATDM>2.0.CO;2.

Gelaro, R., and Coauthors, 2017: The Modern-Era Retrospective Analysis for Research and Applications, version 2 (MERRA-2). J. Climate, 30, 5419-5454, https://doi.org/10.1175/JCLI-D-160758.1.

Grams, C. M., and H. M. Archambault, 2016: The key role of diabatic outflow in amplifying the midlatitude flow: A representative case study of weather systems surrounding western North Pacific extratropical transition. Mon. Wea. Rev., 144, 3847-3869, https://doi.org/10.1175/MWR-D-15-0419.1.

Guan, B., and D. E. Waliser, 2015: Detection of atmospheric rivers: Evaluation and application of an algorithm for global studies. J. Geophys. Res. Atmos., 120, 12 514-12 535, https://doi.org/ 10.1002/2015JD024257.

Hanna, E., J. M. Jones, J. Cappelen, S. H. Mernild, L. Wood, K. Steffen, and P. Huybrechts, 2013: The influence of North Atlantic atmospheric and oceanic forcing effects on 1900-2010 Greenland summer climate and ice melt/runoff. Int. J. Climatol., 33, 862-880, https://doi.org/10.1002/joc.3475.

_- X. Fettweis, and R. J. Hall, 2018a: Brief communication: Recent changes in summer Greenland blocking captured by none of the CMIP5 models. Cryosphere, 12, 3287-3292, https:// doi.org/10.5194/tc-12-3287-2018.

-, R. J. Hall, T. E. Cropper, T. J. Ballinger, L. Wake, T. Mote, and J. Cappelen, 2018b: Greenland blocking index daily series 1851-2015: Analysis of changes in extremes and links with North Atlantic and UK climate variability and change. Int. J. Climatol., 38, 3546-3564, https://doi.org/10.1002/joc.5516.

— , and Coauthors, 2020: Mass balance of the ice sheets and glaciers-Progress since AR5 and challenges. Earth-Sci. Rev., 201, 976, https://doi.org/10.1016/j.earscirev.2019.102976.

Heinemann, G., and U. Falk, 2002: Surface winds and energy fluxes near the Greenland ice margin under conditions of katabatic winds. Polarforschung, 71, 15-31.

Hermann, M., and Coauthors, 2018: Application of PROMICE Q-transect in situ accumulation and ablation measurements (2000-2017) to constrain mass balance at the southern tip of the Greenland ice sheet. J. Geophys. Res. Earth, 123, 1235 1256, https://doi.org/10.1029/2017JF004408.

Hofer, S., A. J. Tedstone, X. Fettweis, and J. L. Bamber, 2017: Decreasing cloud cover drives the recent mass loss on the
Greenland Ice Sheet. Sci. Adv., 3, e1700584, https://doi.org/ 10.1126/SCIADV.1700584.

$\longleftarrow, \ldots,-$, and $\longrightarrow, 2019$ : Cloud microphysics and circulation anomalies control differences in future Greenland melt. Nat. Climate Change, 9, 523-528, https://doi.org/10.1038/ s41558-019-0507-8.

Lavers, D. A., F. M. Ralph, D. E. Waliser, A. Gershunov, and M. D. Dettinger, 2015: Climate change intensification of horizontal water vapor transport in CMIP5. Geophys. Res. Lett., 42, 5617-5625, https://doi.org/10.1002/2015GL064672.

Lenaerts, J. T. M., K. Van Tricht, S. Lhermitte, and T. S. L'Ecuyer, 2017: Polar clouds and radiation in satellite observations, reanalyses, and climate models. Geophys. Res. Lett., 44, 33553364, https://doi.org/10.1002/2016GL072242.

Liu, C., and E. A. Barnes, 2015: Extreme moisture transport into the Arctic linked to Rossby wave breaking. J. Geophys. Res. Atmos., 120, 3774-3788, https://doi.org/10.1002/ 2014JD022796.

Luthcke, S. B., T. Sabaka, B. Loomis, A. Arendt, J. McCarthy, and J. Camp, 2013: Antarctica, Greenland and Gulf of Alaska land-ice evolution from an iterated GRACE global mascon solution. J. Glaciol., 59, 613-631, https://doi.org/10.3189/ 2013JoG12J147.

Mattingly, K. S., C. A. Ramseyer, J. J. Rosen, T. L. Mote, and R. Muthyala, 2016: Increasing water vapor transport to the Greenland Ice Sheet revealed using self-organizing maps. Geophys. Res. Lett., 43, 9250-9258, https://doi.org/10.1002/ 2016 GL070424.

__ T. L. Mote, and X. Fettweis, 2018: Atmospheric river impacts on Greenland Ice Sheet surface mass balance. J. Geophys. Res. Atmos., 123, 8538-8560, https://doi.org/ 10.1029/2018JD028714.

McIlhattan, E. A., T. S. L'Ecuyer, and N. B. Miller, 2017: Observational evidence linking Arctic supercooled liquid cloud biases in CESM to snowfall processes. J. Climate, $\mathbf{3 0}$, 4477-4495, https://doi.org/10.1175/JCLI-D-16-0666.1.

— C. Pettersen, N. B. Wood, and T. S. L'Ecuyer, 2019: Satellite observations of snowfall regimes over the Greenland Ice Sheet. Cryosphere Discuss., https://doi.org/10.5194/tc-2019223 , in press.

McLeod, J. T., and T. L. Mote, 2015: Assessing the role of precursor cyclones on the formation of extreme Greenland blocking episodes and their impact on summer melting across the Greenland ice sheet. J. Geophys. Res. Atmos., 120, 12357 12 377, https://doi.org/10.1002/2015JD023945.

_ , and — 2016: Linking interannual variability in extreme Greenland blocking episodes to the recent increase in summer melting across the Greenland ice sheet. Int. J. Climatol., 36, 1484-1499, https://doi.org/10.1002/joc.4440.

Meesters, A., 1994: Dependence of the energy balance of the Greenland ice sheet on climate change: Influence of katabatic wind and tundra. Quart. J. Roy. Meteor. Soc., 120, 491-517, https://doi.org/10.1002/qj.49712051702.

Miller, N. B., M. D. Shupe, C. J. Cox, V. P. Walden, D. D. Turner, and K. Steffen, 2015: Cloud radiative forcing at Summit, Greenland. J. Climate, 28, 6267-6280, https://doi.org/10.1175/ JCLI-D-15-0076.1.

,,,--- D. Noone, P. O. G. Persson, and K. Steffen, 2017: Surface energy budget responses to radiative forcing at Summit, Greenland. Cryosphere, 11, 497-516, https://doi.org/ 10.5194/tc-11-497-2017.

Miller, P. W., and T. L. Mote, 2018: Characterizing severe weather potential in synoptically weakly forced thunderstorm 
environments. Nat. Hazards Earth Syst. Sci., 18, 1261-1277, https://doi.org/10.5194/nhess-18-1261-2018.

Moore, G. W. K., I. A. Renfrew, and J. J. Cassano, 2013: Greenland plateau jets. Tellus, 65A, 17468, https://doi.org/10.3402/ tellusa.v65i0.17468.

Mouginot, J., and Coauthors, 2019: Forty-six years of Greenland Ice Sheet mass balance from 1972 to 2018. Proc. Natl. Acad. Sci. USA, 116, 9239-9244, https://doi.org/10.1073/pnas. 1904242116.

Mundhenk, B. D., E. A. Barnes, and E. D. Maloney, 2016a: Allseason climatology and variability of atmospheric river frequencies over the North Pacific. J. Climate, 29, 4885-4903, https://doi.org/10.1175/JCLI-D-15-0655.1.

$-,-\ldots,-$, and K. M. Nardi, 2016b: Modulation of atmospheric rivers near Alaska and the U.S. West Coast by northeast Pacific height anomalies. J. Geophys. Res. Atmos. 121, 12 751-12 765, https://doi.org/10.1002/2016JD025350.

Neff, W., G. P. Compo, F. Martin Ralph, and M. D. Shupe, 2014: Continental heat anomalies and the extreme melting of the Greenland ice surface in 2012 and 1889. J. Geophys. Res. Atmos., 119, 6520-6536, https://doi.org/10.1002/2014JD021470.

Nghiem, S., and Coauthors, 2012: The extreme melt across the Greenland ice sheet in 2012. Geophys. Res. Lett., 39, L20502, https://doi.org/10.1029/2012GL053611.

Nicolas, J. P., and Coauthors, 2017: January 2016 extensive summer melt in West Antarctica favoured by strong El Niño. Nat. Commun., 8, 15799, https://doi.org/10.1038/ncomms15799.

Niwano, M., A. Hashimoto, and T. Aoki, 2019: Cloud-driven modulations of Greenland ice sheet surface melt. Sci. Rep., 9, 10380, https://doi.org/10.1038/s41598-019-46152-5.

Noël, B., W. J. van de Berg, E. van Meijgaard, P. Kuipers Munneke, R. S. W. van de Wal, and M. R. van den Broeke, 2015: Evaluation of the updated regional climate model RACMO2.3: Summer snowfall impact on the Greenland ice sheet. Cryosphere, 9, 1831-1844, https://doi.org/10.5194/tc-91831-2015.

,-- , S. Lhermitte, and M. R. van den Broeke, 2019: Rapid ablation zone expansion amplifies north Greenland mass loss. Sci. Adv., 5, eaaw0123, https://doi.org/10.1126/sciadv.aaw0123.

Oltmanns, M., F. Straneo, and M. Tedesco, 2019: Increased Greenland melt triggered by large-scale, year-round cyclonic moisture intrusions. Cryosphere, 13, 815-825, https://doi.org/ 10.5194/tc-13-815-2019.

Parish, T. R., and D. H. Bromwich, 1989: Instrumented aircraft observations of the katabatic wind regime near Terra Nova Bay. Mon. Wea. Rev., 117, 1570-1585, https://doi.org/10.1175/ 1520-0493(1989)117<1570:IAOOTK > 2.0.CO;2.

Pettersen, C., R. Bennartz, M. S. Kulie, A. J. Merrelli, M. D. Shupe, and D. D. Turner, 2016: Microwave signatures of ice hydrometeors from ground-based observations above Summit, Greenland. Atmos. Chem. Phys., 16, 4743-4756, https:// doi.org/10.5194/acp-16-4743-2016.

- - , A. J. Merrelli, M. D. Shupe, D. D. Turner, and V. P. Walden, 2018: Precipitation regimes over central Greenland inferred from 5 years of ICECAPS observations. Atmos. Chem. Phys., 18, 4715-4735, https://doi.org/10.5194/acp-184715-2018.

Pfahl, S., C. Schwierz, M. Croci-Maspoli, C. M. Grams, and H. Wernli, 2015: Importance of latent heat release in ascending air streams for atmospheric blocking. Nat. Geosci., 8 , 610-614, https://doi.org/10.1038/ngeo2487.

Rae, J. G. L., and Coauthors, 2012: Greenland ice sheet surface mass balance: Evaluating simulations and making projections with regional climate models. Cryosphere, 6, 1275-1294, https://doi.org/10.5194/tc-6-1275-2012.

Rajewicz, J., and S. J. Marshall, 2014: Variability and trends in anticyclonic circulation over the Greenland ice sheet, 19482013. Geophys. Res. Lett., 41, 2842-2850, https://doi.org/ 10.1002/2014GL059255.

Rückamp, M., U. Falk, S. Lange, K. Frieler, and A. Humbert, 2018: The effect of overshooting $1.5^{\circ} \mathrm{C}$ global warming on the mass loss of the Greenland ice sheet. Earth Syst. Dyn., 9, 1169-1189, https://doi.org/10.5194/esd-9-1169-2018.

Shepherd, A., and Coauthors, 2020: Mass balance of the Greenland Ice Sheet from 1992 to 2018. Nature, 579, 233-239, https:// doi.org/10.1038/s41586-019-1855-2.

Shupe, M. D., and Coauthors, 2013: High and dry: New observations of tropospheric and cloud properties above the Greenland Ice Sheet. Bull. Amer. Meteor. Soc., 94, 169-186, https://doi.org/10.1175/BAMS-D-11-00249.1.

Singh, H. K. A., C. M. Bitz, A. Donohoe, and P. J. Rasch, 2017: A source-receptor perspective on the polar hydrologic cycle: Sources, seasonality, and Arctic-Antarctic parity in the hydrologic cycle response to $\mathrm{CO}_{2}$ doubling. J. Climate, 30, 9999 10 017, https://doi.org/10.1175/JCLI-D-16-0917.1.

Smeets, C. J. P. P., and M. R. van den Broeke, 2008: Temporal and spatial variations of the aerodynamic roughness length in the ablation zone of the Greenland ice sheet. Bound.-Layer Meteor., 128, 315-338, https://doi.org/10.1007/s10546-0089291-0.

Solomon, A., M. D. Shupe, and N. B. Miller, 2017: Cloudatmospheric boundary layer-surface interactions on the Greenland Ice Sheet during the July 2012 extreme melt event. J. Climate, 30, 3237-3252, https://doi.org/10.1175/JCLI-D-160071.1.

Sutterley, T. C., I. Velicogna, X. Fettweis, E. Rignot, B. Noël, and M. van den Broeke, 2018: Evaluation of reconstructions of snow/ice melt in Greenland by regional atmospheric climate models using laser altimetry data. Geophys. Res. Lett., 45, 8324-8333, https://doi.org/10.1029/2018GL078645.

Tedesco, M., S. Doherty, X. Fettweis, P. Alexander, J. Jeyaratnam, and J. Stroeve, 2016: The darkening of the Greenland ice sheet: Trends, drivers, and projections (1981-2100). Cryosphere, 10, 477-496, https://doi.org/10.5194/tc-10-477-2016.

Turner, D. D., S. A. Clough, J. C. Liljegren, E. E. Clothiaux, K. E. Cady-Pereira, and K. L. Gaustad, 2007: Retrieving liquid water path and precipitable water vapor from the Atmospheric Radiation Measurement (ARM) microwave radiometers. IEEE T. Geosci. Remote, 45, 3680-3690, https://doi.org/10.1109/ TGRS.2007.903703.

Välisuo, I., T. Vihma, R. Pirazzini, and M. Schäfer, 2018: Interannual variability of atmospheric conditions and surface melt in Greenland in 2000-2014. J. Geophys. Res. Atmos., 123, 10 443-10 463, https://doi.org/10.1029/2018JD028445.

van Angelen, J. H., M. R. van den Broeke, and W. J. van de Berg, 2011: Momentum budget of the atmospheric boundary layer over the Greenland ice sheet and its surrounding seas. J. Geophys. Res., 116, D10101, https://doi.org/10.1029/ 2010JD015485.

van As, D., 2011: Warming, glacier melt and surface energy budget from weather station observations in the Melville Bay region of northwest Greenland. J. Glaciol., 57, 208-220, https:// doi.org/10.3189/002214311796405898.

, and Coauthors, 2011: Programme for Monitoring of the Greenland Ice Sheet (PROMICE): First temperature and 
ablation record. Geol. Surv. Denmark Greenl. Bull., 23, 73-76, https://doi.org/10.34194/geusb.v23.4876.

, A. L. Hubbard, B. Hasholt, A. B. Mikkelsen, M. R. van den Broeke, and R. S. Fausto, 2012: Large surface meltwater discharge from the Kangerlussuaq sector of the Greenland ice sheet during the record-warm year 2010 explained by detailed energy balance observations. Cryosphere, 6, 199-209, https:// doi.org/10.5194/tc-6-199-2012.

— due to the melt-albedo feedback observed at PROMICE weather stations. Geol. Surv. Denmark Greenl. Bull., 28, 6972, https://doi.org/10.34194/geusb.v28.4728.

van den Broeke, M. R., and H. Gallée, 1996: Observation and simulation of barrier winds at the western margin of the Greenland ice sheet. Quart. J. Roy. Meteor. Soc., 122, 13651383, https://doi.org/10.1002/qj.49712253407.

, P. Duynkerke, and J. Oerlemans, 1994: The observed katabatic flow at the edge of the Greenland ice sheet during GIMEX-91. Global Planet. Change, 9, 3-15, https://doi.org/ 10.1016/0921-8181(94)90003-5.

E. M. Enderlin, I. M. Howat, P. Kuipers Munneke, B. P. Y. Noël, W. J. van de Berg, E. van Meijgaard, and B. Wouters, 2016: On the recent contribution of the Greenland ice sheet to sea level change. Cryosphere, 10, 1933-1946, https://doi.org/ 10.5194/tc-10-1933-2016.
- - and Coauthors, 2017: Greenland Ice Sheet surface mass loss: Recent developments in observation and modeling. Curr. Climate Change Rep., 3, 345-356, https://doi.org/10.1007/s40641-017-0084-8.

Van Tricht, K., and Coauthors, 2016: Clouds enhance Greenland ice sheet meltwater runoff. Nat. Commun., 7, 10266, https:// doi.org/10.1038/ncomms10266.

Wang, S., D. Nath, W. Chen, and L. Wang, 2019: Recent strengthening of Greenland blocking drives summertime surface warming over northern Canada and eastern Siberia. J. Climate, 32, 3263-3278, https://doi.org/10.1175/JCLI-D-180410.1.

Wang, W., C. S. Zender, and D. van As, 2018: Temporal characteristics of cloud radiative effects on the Greenland Ice Sheet: Discoveries from multiyear automatic weather station measurements. J. Geophys. Res. Atmos., 123, 11348-11361, https://doi.org/10.1029/2018JD028540.

,,,--- and N. B. Miller, 2019: Spatial distribution of melt season cloud radiative effects over Greenland: Evaluating satellite observations, reanalyses, and model simulations against in situ measurements. J. Geophys. Res. Atmos., 124, 57-71, https://doi.org/10.1029/2018JD028919.

Wille, J. D., V. Favier, A. Dufour, I. V. Gorodetskaya, J. Turner, C. Agosta, and F. Codron, 2019: West Antarctic surface melt triggered by atmospheric rivers. Nat. Geosci., 12, 911-916, https://doi.org/10.1038/s41561-019-0460-1. 